\title{
Capsicum baccatum türüne ait biber popülasyonunun karakterizasyonu ve morfolojik varyasyon düzeyinin belirlenmesi
}

The determination of morphological variation level and characterization of Capsicum baccatum populations

\author{
Aslı KANAL ${ }^{10}$ iD, Ahmet BALKAYA ${ }^{1}$ \\ ${ }^{1}$ Ondokuz Mayıs University, Faculty of Agriculture, Department of Horticulture, Samsun, Turkey.
}

MAKALE BILGISI / ARTICLE INFO

\section{Makale tarihçesi / Article history:}

DOI: $10.37908 /$ mkutbd.889523

Geliş tarihi /Received:02.03.2021

Kabul tarihi/Accepted:04.04.2021

\section{Keywords:}

C. baccatum, diversity, genotype, identification, variation.

\footnotetext{
Corresponding author: Aslı KANAL

$\triangle$ : aslikanal5515@gmail.com
}

\author{
Ö ZET / A B STR A C T
}

Atıf / Citation: Kanal A, Balkaya A (2021) Capsicum baccatum türüne ait biber popülasyonunun karakterizasyonu ve morfolojik varyasyon düzeyinin belirlenmesi. MKU. Tar. Bil. Derg. 26(2) : 278-291. DOI: 10.37908/mkutbd.889523

\section{Gíiş}

Biber bitkisi, Solanaceae familyasında Capsicum cinsi içerisinde yer almaktadır (Greenleaf, 1986). Günümüzde beş tür (Capsicum annuum L., Capsicum baccatum L. var. pendulum, Capsicum chinense Jacq., Capsicum frutescens L. ve C. pubescens Ruiz \& Pav.) kültüre alınmıştır (Eshbaugh, 2012; Barboza ve ark., 2019). C. baccatum türünün günümüzde yabani ve kültüre alınmış formları da vardır. Güney Amerika'da "aji" veya "Peru acı biberi" olarak bilinmektedir (Jarret, 2007; Mavi ve Mavi, 2012). Islahçılar son yıllarda biberde belirtilen bu genetik çeşitlilikten yararlanarak, adaptasyon, verim, kalite, hastalık ve zararlılara dayanıklılık yönünden istenilen özelliklere sahip yeni bitki çeşitlerini seçme veya çeşit geliştirme yolunda önemli düzeyde başarılar elde etmişlerdir (Karaağaç ve Balkaya, 2017).

C. baccatum var. pendulum alt türünün meyveleri taze tüketim yanında, salsa sosu, acı biber sosu ve toz biber üretiminde de kullanılmaktadır (Jarret, 2007). Capsicum baccatum türü, değişik meyve şekillerine, eşsiz bir lezzete ve farklı aromalara sahip olmasına rağmen, Güney Amerika dışında çok fazla tanınan bir biber türü değildir. Ülkemizde $C$. baccatum biber türü, meyveleri çana benzediği için "çan biberi" veya "gül biberi" olarak adlandırılmakta (Eken ve Mavi, 2014) olup henüz C. baccatum türüne ait yetiştiriciliği yapılan ticari bir çeşit bulunmamaktadır (TTSM, 2019). 
Genetik kaynaklar bitkisel özellikleri yönünden tanımlanmadıkları sürece bitki ıslah programlarında yer alması mümkün olmamakta ve çeşit ıslah programlarına alınsa bile kısa süre içerisinde gen erozyonuna uğramaktadırlar (Balkaya ve Yanmaz, 2001; Karaağaç ve Balkaya, 2010). Ülkemizde daha çok $C$. annuum türü üzerinde morfolojik karakterizasyon çalışmaları gerçekleştirilmiştir. Son yıllarda sayıları sınırlı da olsa diğer Capsicum türleri üzerinde bazı çalışmalar yapılmaya başlamıştır (Yaldız ve Özgüven, 2011; Eken ve Mavi, 2014; Mavi ve ark., 2018; Taş, 2020).

Gen havuzlarında var olan mevcut varyasyonun düzeyinin bilinmesi ve bu varyasyonun dağılış durumlarının tespit edilmesi çeşit ıslah programlarının uygulanmasında çok önemlidir (Bliss, 1981; Balkaya ve ark., 2010). Biber popülasyonları içerisinde fenotipik çeşitlilik düzeyi oldukça fazladır. Çeşitliliği ortaya çıkaran unsurlar; meyve şekli, rengi, meyvede acılık oranı, meyve et kalınlığı, meyve et rengi, meyve büyüklüğü ve tohum sayısı vb. gibi özelliklerden kaynaklanmaktadır (GarcíaNeria ve Rivera-Bustamante, 2011). Bu araştırmada, Dünya'nın farklı lokasyonlarından toplanmış olan $C$. baccatum türüne ait genetik kaynakların UPOV (Uluslararası Yeni Bitki Çeşitlerini Koruma Birliği) bitki özellik belgesi kriterlerine göre morfolojik özelliklerinin tanımlanması ve popülasyonda var olan mevcut varyasyon düzeyinin belirlenmesi ile varyasyonu oluşturan faktörlerin hangi özelliklerden kaynaklandığının ayrıntılı olarak tespit edilmesi amaçlanmıştır.

Çizelge 1. C. baccatum biber popülasyonunda yer alan genotiplere ait kayıt bilgileri ve orijinleri

Table 1. Accession number and data on the origin site of the C. baccatum populations studied

\begin{tabular}{|c|c|c|c|c|c|}
\hline Genotipler & Kayıt numarası & Orijini & Genotipler & Kayıt numarası & Orijini \\
\hline \multicolumn{3}{|c|}{ Capsicum baccatum var. baccatum } & \multicolumn{3}{|c|}{ Capsicum baccatum var. pendulum (devamı) } \\
\hline CB-1 & PI 15925201 SD & $A B D$ & CB-50 & PI 44156801 SD & Brezilya \\
\hline CB-2 & PI 58524202 SD & Ekvador & CB-51 & PI 44156201 SD & Brezilya \\
\hline CB-3 & PI 58524302 SD & Ekvador & CB-52 & PI 15926001 SD & $A B D$ \\
\hline CB-4 & PI 23806101 SD & Bolivya & CB-53 & PI 28130001 SD & Arjantin \\
\hline CB-6 & PI 21569901 SD & Peru & CB-55 & PI 26604201 SD & Meksika \\
\hline CB-11 & PI 43952801 SD & Brezilya & CB-56 & PI 26056501 SD & Bolivya \\
\hline CB-12 & PI 59605901 SD & Bolivya & CB-57 & PI 26055901 SD & Bolivya \\
\hline CB-16 & PI 63292201 SD & Paraguay & CB-58 & PI 26772901 SD & Bolivya \\
\hline CB-17 & PI 63375202 SD & Paraguay & CB-59 & PI 26057201 SD & Bolivya \\
\hline CB-18 & PI 63115003 SD & Paraguay & CB-60 & PI 15925901 SD & $A B D$ \\
\hline CB-20 & PI 28130901 SD & Peru & CB-61 & PI 23806201 SD & Brezilya \\
\hline \multicolumn{3}{|c|}{ Capsicum baccatum var. pendulum } & CB-62 & PI 15927201 SD & ABD \\
\hline CB-21 & PI 25716901 SD & Peru & CB-64 & PI 65367004 SD & Kosta Rika \\
\hline CB-22 & PI 25717901 SD & Peru & CB-65 & PI 44154101 SD & Brezilya \\
\hline CB-23 & PI 25717401 SD & Peru & CB-66 & PI 44155201 SD & Brezilya \\
\hline CB-27 & PI 26054501 SD & Brezilya & CB-67 & PI 44158401 SD & Brezilya \\
\hline CB-28 & PI 26053801 SD & Arjantin & CB-68 & PI 24165801 SD & Peru \\
\hline CB-29 & PI 26048801 SD & Bolivya & CB-69 & PI 44151901 SD & Brezilya \\
\hline CB-31 & PI 25716801 SD & Peru & CB-70 & PI 43940901 SD & Uruguay \\
\hline CB-33 & PI 25713401 SD & Ekvator & CB-71 & PI 26059301 SD & Brezilya \\
\hline CB-34 & PI 25713301 SD & Ekvator & $\mathrm{CB}-72$ & PI 33752301 SD & Arjantin \\
\hline CB-36 & PI 26053601 SD & Arjantin & CB-73 & PI 59050601 SD & Bolivya \\
\hline CB-38 & PI 25712201 SD & Colombia & CB-74 & PI 58524401 SD & Ekvador \\
\hline CB-39 & PI 28132001 SD & Şili & CB-75 & PI 58524001 SD & Ekvador \\
\hline CB-40 & PI 26055201 SD & Peru & CB-76 & PI 63292502 SD & Paraguay \\
\hline CB-41 & PI 28131101 SD & Brezilya & CB-77 & PI 63375601 SD & Paraguay \\
\hline CB-42 & PI 33752201 SD & Arjantin & CB-78 & Grif 919601 SD & Kosta Rika \\
\hline CB-44 & PI 59413601 SD & Macaristan & $\mathrm{CB}-82$ & PI 24167901 SD & Şili \\
\hline CB-45 & PI 59393201 SD & Ekvador & CB-83 & PI 18848101 SD & Peru \\
\hline CB-46 & PI 43941101 SD & Uruguay & CB-84 & PI 28130701 SD & Bolivya \\
\hline CB-47 & PI 43941001 SD & Uruguay & CB-85 & PI 44155401 SD & Brezilya \\
\hline CB-48 & PI 44153101 SD & Brezilya & CB-86 & PI 58524902 SD & Ekvador \\
\hline CB-49 & PI 44153301 SD & Brezilya & CB-87 & PI 58525001 SD & Ekvador \\
\hline
\end{tabular}




\section{MATERYAL ve YÖNTEM}

Bu araştırma, 2018-2019 yıllarında Ondokuz Mayıs Üniversitesi Ziraat Fakültesi Bahçe Bitkileri Bölümünde yürütülmüştür. Araştırmada, Amerika kıtasının farklı ülkelerinden toplanmış olan $C$. baccatum türüne ait 67 adet biber genotipi kullanılmıştır. Bu genetik materyaller, Amerika Tarım Bakanlığı Tohum Gen Bankasından (USDA-ARS-National Plant Germplasm System) temin edilmiştir. Bunlardan 10 tanesi $C$. baccatum var. baccatum ve 57 tanesi ise $C$. baccatum var. pendulum türüne aittir. İncelenen $C$. baccatum biber popülasyonunda yer alan genetik materyallere ait kayıt bilgileri, Çizelge 1 'de sunulmuştur. C. baccatum türüne ait biber genotiplerinin tohum ekimleri, 5 Mart 2018 tarihinde viyollere yapılmıştır. $C$. baccatum türüne ait biber fideleri, 4-5 gerçek yapraklı olduğu döneme kadar $25^{\circ} \mathrm{C} \pm 2^{\circ} \mathrm{C}$ sıcaklık kontrollü sera ünitesinde yetiştirilmiştir. Denemede, 67 biber genotipinin her birinden 18 'er adet biber fidesi, $50 \times 50 \mathrm{~cm}$ sıra arası ve sıra üzeri mesafe ile 25 Nisan 2018 tarihinde dikilmiştir. Dikilen 18 bitkiden, 12 tanesinde morfolojik karakterizasyon ve diğer 6 bitkide ise biber seleksiyon ıslahı için mevcut genotiplerde ıslah kademesinin ilerlemesini sağlamak amacıyla kendileme işlemi gerçekleştirilmiştir. C. baccatum türüne ait biber gen kaynaklarında morfolojik karakterizasyon, Uluslararası Yeni Bitki Çeşitlerini Koruma Birliği (UPOV) tarafından biber için belirtilen TG/76/8 nolu bitki çeşit özellik belgesine göre tarafımızdan modifiye edilerek yapılmıştır (UPOV, 2006). Bu kriterler, Çizelge 2'de ayrıntılı olarak sunulmuştur.

Son yıllarda, çoklu değişken analizleri olarak adlandırılan taksonomik sınıflandırma yöntemleri ile popülasyonlardaki var olan mevcut varyasyonun düzeyi belirlenebilmektedir. C. baccatum türüne ait biber popülasyonlarının morfolojik karakterizasyonları yapıldıktan sonra elde edilen verilerin istatistiksel analizleri, SPSS (15.0 for windows) paket programı kullanılarak gerçekleştirilmiştir. Çalışmada, biber genotiplerinin birbirleri ile benzerlik ve farklılıklarını gösteren "Gruplar arası benzerlik" dendrogramı oluşturulmuştur. Bu dendrogram Ward metoduna göre Cluster (küme) analizinin yapılması ile elde edilmiştir (Rohlf, 1993; Balkaya ve ark., 2005; Karaağaç, 2006, Karaağaç ve Balkaya, 2010).

Çizelge 2. C. baccatum türüne ait genotiplerin morfolojik karakterizasyonunda incelenen kriterler

Table 2. Morphological traits used in C. baccatum populations characterization

\begin{tabular}{|c|c|c|}
\hline 1. & Bitki duruşu & Dik, yarı dik ve yatık olarak sınıflandırılmıştır. \\
\hline 2. & Bitki boyu $(\mathrm{cm})$ & \\
\hline 3. & Antosiyonin oluşumu & Yok veya var şeklinde değerlendirilmiştir. \\
\hline 4. & Antosiyonin yoğunluğu & Çok zayıf, zayıf, orta, kuvvetli ve çok kuvvetli şeklinde belirlenmiştir \\
\hline 5. & Gövde kalınlığı (mm) & $\begin{array}{l}\text { Bitkini gövdesi, meyvelerin \%50 hasat olgunluğuna geldiğinde } \\
\text { toprak yüzeyinin } 5 \mathrm{~cm} \text { üzerinden gövde çapı ölçülmüştür. }\end{array}$ \\
\hline 6. & Yaprak boyu $(\mathrm{cm})$ & $\begin{array}{l}\text { Her bir bitkiden tam yaprak büyüklüğünde olan } 12 \text { adet yaprağın boyu ölçülmüş ve } \\
\text { ortalama yaprak boyu değerleri belirlenmiştir. }\end{array}$ \\
\hline 7. & Yaprak eni $(\mathrm{cm})$ & Yaprağın orta kısmı, cetvel yardmı ile en uzak mesafe olacak şekilde ölçülmüştür. \\
\hline 8. & Yaprak şekli & Delta, yumurta ve mızrak şeklinde değerlendirilmiştir. \\
\hline 9. & Yaprak rengi (görsel) & Açık yeşil, yeşil ve koyu yeşil renk tonları olarak tanımlanmıştır. \\
\hline 10. & Çiçek rengi & Mor, beyaz veya beyaz-sarı renk tonu olarak belirlenmiştir \\
\hline 11. & Meyve duruşu & Dik, yarı dik ve sarkık olarak sınıflandırılmıştır. \\
\hline 12. & Meyve boyu (mm) & \\
\hline 13. & Meyve eni (mm) & \\
\hline 14. & Meyve şekil indeksi & Meyve boyunun, meyve enine oranlanması ile saptanmıştır. \\
\hline 15. & Meyve sap uzunluğu (mm) & \\
\hline 16. & Meyve şekli & Yuvarlak, kalp, kare, çan, üçgen, boynuz, şeklinde tanımlanmıştır \\
\hline 17. & Meyve uç şekli & Çok sivri, sivri, yuvarlak, hafif basık, basık ve çok basık şeklinde sınıflandırılmıştır. \\
\hline 18. & Sap çukuru şekli & Derin, az derin ve yok şeklinde tanımlanmıştır \\
\hline 19. & Meyve rengi (görsel) & Taze tüketim için hasat olum döneminde koyu yeşil, yeşil, açık yeşil olarak tanımlanmıştır \\
\hline 20. & Ortalama meyve ağırlığı (g) & $\begin{array}{l}\text { Hasat döneminde her bitkiden hasat edilen tüm meyvelerin toplam ağırlıklarının, toplam } \\
\text { meyve sayısına oranlanması ile hesaplanmıştır. }\end{array}$ \\
\hline 21. & Bitki başına meyve sayısı (adet) & Hasat döneminde her bir bitkiden hasat edilen meyvelerin sayılması ile tespit edilmiştir. \\
\hline 22. & Bitki başına meyve ağırlığı (g) & $\begin{array}{l}\text { Genotiplere ait tüm biberlerden hasat edilen meyveler hassas terazide tartılarak ( } 0.001 \mathrm{~g}) \\
\text { ortalamaları alınmıştır. }\end{array}$ \\
\hline 23. & $\begin{array}{l}\text { Meyvede kuru madde miktarı } \\
\text { (g) }\end{array}$ & $\begin{array}{l}\text { Her bir genotipten alınan birbirine benzer } 5 \text { adet meyvenin } 80^{\circ} \mathrm{C} \text { etüvde } 72 \text { saat kuruması } \\
\text { için bırakılmıştır (Karaağaç, 2013). Kuru meyve ağırlıkları, hassas terazide ( } 0.001 \mathrm{~g} \text { ) } \\
\text { tartılarak belirlenmiştir. }\end{array}$ \\
\hline
\end{tabular}




\section{BULGULAR ve TARTIŞMA}

Araştırmada incelenen genotiplerin; \%34.3'ünün dik, $\% 61.1^{\prime}$ inin yarı dik ve $\% 4.6$ 'sının ise yatık olarak büyüme gösterdikleri saptanmıştır (Çizelge 3). Büyüme şekli yönünden $C$. baccatum genotiplerinin büyük bir çoğunluğunun yarı dik büyüme formu gösterdikleri tespit edilmiştir. $C$. baccatum türüne ait biber genotiplerinde en yüksek bitki boyu değerleri sırasıyla CB-68 $(47.1 \mathrm{~cm})$, CB-85 $(47.0 \mathrm{~cm}), \mathrm{CB}-21(46.7 \mathrm{~cm}), \mathrm{CB}-49(46.6 \mathrm{~cm})$ ve CB$28(46.6 \mathrm{~cm})$ genotiplerinde ölçülmüştür.

Çizelge 3. C. baccatum türüne ait biber genotiplerinin bitki duruşu, bitki boyu ve gövde kalınlığı özelliklerine ait sonuçlar Table 3. The results of plant growth habit, plant length and stem diameter traits of $C$. baccatum genotypes

\begin{tabular}{|c|c|c|c|c|c|c|c|c|}
\hline Genotip No & $\begin{array}{l}\text { Bitki } \\
\text { Duruşu }\end{array}$ & Bitki Boyu (cm) & $\begin{array}{l}\text { Gövde Kalınlığı } \\
\text { (mm) }\end{array}$ & $\begin{array}{l}\text { Genotip } \\
\text { No }\end{array}$ & Bitki Duruşu & Bitki Boyu $(\mathrm{cm})$ & $\begin{array}{l}\text { Gövde } \\
(\mathrm{mm})\end{array}$ & Kalınlığı \\
\hline CB-1 & Yatık & $16.5 \pm 0.6$ & $9.4 \pm 1.1$ & CB-51 & Yarı dik & $30.4 \pm 4.1$ & $9.6 \pm 0.3$ & \\
\hline CB-2 & Dik & $33.0 \pm 3.8$ & $8.0 \pm 0.8$ & CB-52 & Yarı dik & $42.5 \pm 5.8$ & $11.7 \pm 0.7$ & \\
\hline CB-3 & Yarı dik & $25.2 \pm 2.1$ & $7.9 \pm 2.1$ & CB-53 & Yarı dik & $40.0 \pm 3.4$ & $12.2 \pm 1.2$ & \\
\hline CB-4 & Yarı dik & $20.2 \pm 2.7$ & $10.8 \pm 1.2$ & CB-55 & Yarı dik & $36.1 \pm 3.5$ & $10.5 \pm 1.1$ & \\
\hline CB-6 & Dik & $37.6 \pm 4.8$ & $9.2 \pm 1.0$ & CB-56 & Yarı dik & $32.7 \pm 3.3$ & $11.5 \pm 0.5$ & \\
\hline CB-11 & Dik & $39.1 \pm 2.8$ & $10.7 \pm 2.8$ & CB-57 & Yarı dik & $30.9 \pm 4.1$ & $7.6 \pm 0.3$ & \\
\hline CB-12 & Yarı dik & $29.6 \pm 2.6$ & $9.2 \pm 1.3$ & CB-58 & Yarı dik & $24.9 \pm 4.8$ & $7.5 \pm 1.2$ & \\
\hline CB-16 & Yarı dik & $34.1 \pm 3.0$ & $10.5 \pm 0.9$ & CB-59 & Yarı dik & $39.2 \pm 0.7$ & $8.4 \pm 1.3$ & \\
\hline CB-17 & Yarı dik & $30.2 \pm 6.6$ & $12.7 \pm 2.1$ & CB-60 & Dik & $34.2 \pm 1.6$ & $10.2 \pm 1.4$ & \\
\hline CB-18 & Yarı dik & $35.6 \pm 3.2$ & $11.1 \pm 1.5$ & CB-61 & Yarı dik & $29.5 \pm 7.4$ & $7.2 \pm 1.3$ & \\
\hline CB-20 & Yarı dik & $37.7 \pm 5.2$ & $12.4 \pm 4.5$ & CB-62 & Yarı dik & $31.3 \pm 1.4$ & $8.8 \pm 0.9$ & \\
\hline CB-21 & Dik & $46.7 \pm 3.1$ & $13.9 \pm 3.3$ & CB-63 & Dik & $36.9 \pm 3.2$ & $11.6 \pm 1.9$ & \\
\hline CB-22 & Dik & $44.9 \pm 8.2$ & $14.3 \pm 3.7$ & CB-64 & Dik & $38.1 \pm 2.4$ & $12.5 \pm 0.2$ & \\
\hline CB-23 & Yarı dik & $45.1 \pm 1.4$ & $12.1 \pm 3.1$ & CB-65 & Dik & $41.8 \pm 1.8$ & $11.6 \pm 1.4$ & \\
\hline CB-27 & Dik & $44.3 \pm 4.3$ & $12.8 \pm 0.3$ & CB-66 & Dik & $40.2 \pm 9.8$ & $13.4 \pm 3.8$ & \\
\hline CB-28 & Dik & $46.6 \pm 3.2$ & $11.4 \pm 1.1$ & CB-67 & Dik & $46.3 \pm 5.4$ & $13.9 \pm 0.8$ & \\
\hline CB-29 & Dik & $43.3 \pm 3.3$ & $12.0 \pm 2.8$ & CB-68 & Dik & $47.1 \pm 5.7$ & $16.1 \pm 2.7$ & \\
\hline CB-31 & Yarı dik & $37.0 \pm 4.4$ & $9.5 \pm 0.8$ & CB-69 & Yarı dik & $43.5 \pm 9.3$ & $14.2 \pm 0.2$ & \\
\hline CB-33 & Dik & $44.8 \pm 1.5$ & $12.2 \pm 1.3$ & CB-70 & Yarı dik & $36.6 \pm 4.5$ & $12.5 \pm 2.1$ & \\
\hline CB-34 & Yarı dik & $33.3 \pm 2.5$ & $11.0 \pm 2.0$ & CB-71 & Yarı dik & $40.9 \pm 4.6$ & $11.0 \pm 0.5$ & \\
\hline CB-36 & Dik & $40.4 \pm 1.2$ & $11.9 \pm 0.9$ & CB-72 & Yarı dik & $35.5 \pm 6.1$ & $14.2 \pm 2.6$ & \\
\hline CB-37 & Yarı dik & $33.2 \pm 2.4$ & $10.3 \pm 1.5$ & CB-73 & Yatık & $29.8 \pm 4.6$ & $13.0 \pm 1.7$ & \\
\hline CB-38 & Yarı dik & $35.8 \pm 3.5$ & $11.2 \pm 0.8$ & CB-74 & Yarı dik & $39.9 \pm 1.1$ & $14.7 \pm 1.1$ & \\
\hline CB-39 & Yarı dik & $38.3 \pm 2.1$ & $15.1 \pm 0.7$ & CB-75 & Yarı dik & $36.7 \pm 2.3$ & $9.9 \pm 0.6$ & \\
\hline CB-40 & Yatık & $27.2 \pm 3.4$ & $9.8 \pm 1.2$ & CB-76 & Yarı dik & $37.9 \pm 1.8$ & $11.0 \pm 1.7$ & \\
\hline CB-41 & Dik & $46.5 \pm 6.1$ & $12.3 \pm 2.1$ & CB-77 & Dik & $46.2 \pm 5.2$ & $12.7 \pm 0.7$ & \\
\hline CB-42 & Dik & $40.1 \pm 4.3$ & $13.7 \pm 3.1$ & CB-78 & Yarı dik & $42.2 \pm 5.4$ & $12.1 \pm 2.6$ & \\
\hline CB-44 & Yarı dik & $35.1 \pm 4.1$ & $9.5 \pm 1.0$ & CB-82 & Yarı dik & $44.2 \pm 7.1$ & $13.5 \pm 2.5$ & \\
\hline CB-45 & Yarı dik & $35.9 \pm 3.7$ & $13.2 \pm 0.9$ & CB-83 & Yarı dik & $43.9 \pm 4.7$ & $13.5 \pm 2.6$ & \\
\hline CB-46 & Yarı dik & $34.4 \pm 3.2$ & $11.3 \pm 1.6$ & CB-84 & Yarı dik & $40.1 \pm 2.2$ & $14.2 \pm 1.0$ & \\
\hline CB-47 & Yarı dik & $35.7 \pm 5.8$ & $12.5 \pm 1.6$ & CB-85 & Dik & $47.0 \pm 8.2$ & $12.8 \pm 2.0$ & \\
\hline CB-48 & Yarı dik & $37.5 \pm 3.2$ & $10.7 \pm 1.4$ & CB-86 & Yarı dik & $43.3 \pm 8.7$ & $13.8 \pm 2.5$ & \\
\hline CB-49 & Dik & $46.6 \pm 10.6$ & $11.7 \pm 3.0$ & CB-87 & Dik & $46.1 \pm 5.3$ & $14.6 \pm 1.6$ & \\
\hline CB-50 & Yarı dik & $31.7 \pm 4.2$ & $9.3 \pm 0.4$ & & & & & \\
\hline
\end{tabular}

En kısa bitki boyuna sahip biber genotipleri ise sırasıyla CB-1 $(16.5 \mathrm{~cm})$, CB-4 $(20.2 \mathrm{~cm})$ ve CB-58 $(24.9 \mathrm{~cm})$ genotipleri olarak belirlenmiştir (Çizelge 3). Genotipler arasında bitki boyu yönünden yaklaşık 2-3 kat arasında belirgin farklılıkların olduğu bulunmuştur. Capsicum türleri bitki boyları yönünden belirgin farklılıklar göstermektedir. Padilha ve ark. (2016), C. annuum türüne ait biber genotiplerinin bitki boylarının 23.12$48.72 \mathrm{~cm}$ ve Sreenivas ve ark. (2019), $37.6 \mathrm{~cm}-110.6 \mathrm{~cm}$ arasında değiştiğini belirlemişlerdir. Mavi ve Mavi (2015) süs biberinde $14.3 \mathrm{~cm}-77.3 \mathrm{~cm}$, Yaldız ve Özgüven (2011) C. frutescens türünde $37.67 \mathrm{~cm}-117.7 \mathrm{~cm}$, Taş (2020) C. chinense türünde $30.5 \mathrm{~cm}-106.0 \mathrm{~cm}$ ve Patel ve ark. (2016) C. baccatum genotiplerinde $27 \mathrm{~cm}-125 \mathrm{~cm}$ arasında bitki boylarının değişim gösterdiğini bildirmişlerdir. Araştırma sonuçları, genotiplere göre değişmekle birlikte genel olarak belirtilen literatürü destekler nitelikte olmuştur. 
Gövde antosiyanin renklenmesi yönünden yapılan incelemede; genotiplerin \%16.5'inde antosiyanin renklenmesinin olmadığı belirlenmiştir. C. baccatum biber genotiplerinin \%34.3'ünde az yoğunlukta, \%32.8'inde çok yoğun, \%16.4'ünde orta yoğunlukta antosiyanin renklenmesinin olduğu belirlenmiştir. Ayrıca gövde kalınlığı değerleri yönünden biber popülasyonunda belirgin farklılıklar (7.2-16.1 $\mathrm{mm}$ ) olduğu saptanmıştır (Çizelge 3). Taş (2020), C. chinense türüne ait biber genotiplerinde gövde çapının $11.2 \mathrm{~mm}$ $27.5 \mathrm{~mm}$ arasında değişim gösterdiğini bildirmiştir. Araştırma sonuçları, C. baccatum türünde genotiplere göre değişmekle birlikte gövde çapının $C$. chinense türüne göre daha düşük olduğunu göstermiştir. Gen havuzunda $C$. baccatum biber çiçek renkleri beyaz-sarı tonlarında olduğu tespit edilmiştir.

Çizelge 4. Capsicum baccatum türüne ait biber genotiplerinin meyve boyutlarına ilişkin sonuçlar Table 4. Results on fruit dimensions of C.baccatum genotypes

\begin{tabular}{|c|c|c|c|c|c|c|c|}
\hline $\begin{array}{c}\text { Genotip } \\
\text { No }\end{array}$ & $\begin{array}{c}\text { Boy } \\
(\mathrm{mm})\end{array}$ & $\begin{array}{c}\mathrm{En} \\
(\mathrm{mm})\end{array}$ & $\begin{array}{c}\text { Şekil } \\
\text { İndeksi }\end{array}$ & $\begin{array}{c}\text { Genotip } \\
\text { No }\end{array}$ & $\begin{array}{c}\text { Boy } \\
(\mathrm{mm})\end{array}$ & $\begin{array}{c}\text { En } \\
(\mathrm{mm})\end{array}$ & Şekil İndeksi \\
\hline CB-1 & $17.1 \pm 0.5$ & $14.0 \pm 0.1$ & 1.2 & CB-51 & $57.4 \pm 10.1$ & $9.6 \pm 1.7$ & 6.0 \\
\hline CB-2 & $81.2 \pm 13.5$ & $22.4 \pm 5.7$ & 3.6 & CB-52 & $72.6 \pm 14.1$ & $10.8 \pm 2.1$ & 6.7 \\
\hline CB-3 & $53.4 \pm 7.1$ & $13.5 \pm 2.2$ & 4 & CB-53 & $74.2 \pm 12.9$ & $17.7 \pm 4.4$ & 4.2 \\
\hline CB-4 & $13.6 \pm 3.2$ & $7.5 \pm 0.9$ & 1.8 & CB-55 & $41.2 \pm 6.3$ & $10.8 \pm 1.6$ & 3.8 \\
\hline CB-6 & $56.5 \pm 16.5$ & $14.1 \pm 4.4$ & 4 & CB-56 & $57.6 \pm 9.4$ & $10.0 \pm 1.4$ & 5.8 \\
\hline CB-11 & $26.8 \pm 12.6$ & $7.9 \pm 0.9$ & 3.4 & CB-57 & $57.2 \pm 10.3$ & $13.7 \pm 2.3$ & 4.2 \\
\hline CB-12 & $13.4 \pm 1.9$ & $6.3 \pm 0.8$ & 2.1 & CB-58 & $55.0 \pm 14.4$ & $19.0 \pm 6.9$ & 2.9 \\
\hline CB-16 & $20.3 \pm 6.1$ & $10.0 \pm 1.6$ & 2 & CB-59 & $40.9 \pm 12.0$ & $10.6 \pm 2.3$ & 3.8 \\
\hline CB-17 & $50.1 \pm 5.6$ & $10.6 \pm 1.7$ & 4.7 & CB-60 & $77.9 \pm 16.6$ & $14.3 \pm 2.2$ & 5.5 \\
\hline CB-18 & $32.5 \pm 5.2$ & $9.6 \pm 1.1$ & 3.4 & CB-61 & $36.4 \pm 15.2$ & $13.9 \pm 2.4$ & 2.6 \\
\hline CB-20 & $16.0 \pm 4.1$ & $15.7 \pm 2.2$ & 1.1 & CB-62 & $55.9 \pm 6.7$ & $21.0 \pm 5.1$ & 2.7 \\
\hline CB-21 & $116.8 \pm 5.2$ & $10.8 \pm 1.3$ & 10.8 & CB-63 & $60.7 \pm 5.2$ & $18.1 \pm 3.7$ & 3.4 \\
\hline $\mathrm{CB}-22$ & $91.1 \pm 5.4$ & $13.6 \pm 2.8$ & 6.7 & CB-64 & $88.2 \pm 5.7$ & $16.1 \pm 3.1$ & 5.5 \\
\hline CB-23 & $55.6 \pm 4.8$ & $10.4 \pm 1.6$ & 5.4 & CB-65 & $32.5 \pm 4.0$ & $21.0 \pm 3.1$ & 1.5 \\
\hline CB-27 & $20.3 \pm 5.1$ & $25.4 \pm 6.3$ & 0.8 & CB-66 & $28.7 \pm 3.7$ & $24.8 \pm 2.6$ & 1.2 \\
\hline CB-28 & $93.9 \pm 8.0$ & $13.9 \pm 3.5$ & 6.8 & CB-67 & $22.1 \pm 3.9$ & $25.4 \pm 3.7$ & 0.9 \\
\hline CB-29 & $78.0 \pm 4.1$ & $17.4 \pm 3.0$ & 4.5 & CB-68 & $49.1 \pm 4.9$ & $18.6 \pm 3.1$ & 2.6 \\
\hline CB-31 & $61.6 \pm 4.8$ & $10.3 \pm 1.6$ & 6 & CB-69 & $21.5 \pm 3.5$ & $26.2 \pm 4.2$ & 0.8 \\
\hline CB-33 & $71.8 \pm 3.2$ & $16.1 \pm 2.4$ & 4.5 & CB-70 & $35.1 \pm 4.1$ & $22.8 \pm 4.3$ & 1.5 \\
\hline CB-34 & $32.1 \pm 3.8$ & $24.4 \pm 3.1$ & 1.3 & CB-71 & $41.9 \pm 5.9$ & $10.4 \pm 2.6$ & 4.0 \\
\hline CB-36 & $51.5 \pm 5.7$ & $16.5 \pm 6.3$ & 3.1 & CB-72 & $41.1 \pm 5.6$ & $10.7 \pm 3.6$ & 3.9 \\
\hline CB-37 & $74.6 \pm 6.8$ & $13.2 \pm 2.1$ & 5.7 & CB-73 & $46.2 \pm 5.1$ & $13.3 \pm 2.4$ & 3.5 \\
\hline CB-38 & $63.6 \pm 3.8$ & $12.6 \pm 2.4$ & 5.1 & CB-74 & $31.4 \pm 3.3$ & $22.9 \pm 3.6$ & 1.4 \\
\hline CB-39 & $73.1 \pm 4.6$ & $16.8 \pm 3.2$ & 4.4 & CB-75 & $76.1 \pm 3.8$ & $16.9 \pm 3.3$ & 4.5 \\
\hline CB-40 & $18.4 \pm 2.6$ & $8.1 \pm 1.0$ & 2.3 & CB-76 & $35.3 \pm 2.8$ & $21.6 \pm 2.8$ & 1.6 \\
\hline CB-41 & $66.3 \pm 5.1$ & $10.4 \pm 1.9$ & 6.4 & CB-77 & $68.1 \pm 3.7$ & $22.8 \pm 5.2$ & 3.0 \\
\hline CB-42 & $47.6 \pm 5.8$ & $9.1 \pm 1.4$ & 5.2 & CB-78 & $62.8 \pm 5.3$ & $17.0 \pm 2.7$ & 3.7 \\
\hline CB-44 & $74.5 \pm 5.6$ & $13.2 \pm 3.2$ & 5.7 & CB-82 & $71.9 \pm 3.2$ & $13.3 \pm 3.1$ & 5.4 \\
\hline CB-45 & $76.1 \pm 3.6$ & $15.7 \pm 2.4$ & 4.9 & CB-83 & $27.1 \pm 5.1$ & $18.8 \pm 3.8$ & 1.4 \\
\hline CB-46 & $31.1 \pm 3.9$ & $26.3 \pm 4.3$ & 1.2 & CB-84 & $55.1 \pm 4.1$ & $9.7 \pm 2.5$ & 5.7 \\
\hline CB-47 & $31.8 \pm 5.2$ & $26.1 \pm 4.3$ & 1.2 & CB-85 & $68.1 \pm 4.1$ & $13.1 \pm 2.4$ & 5.2 \\
\hline CB-48 & $76.4 \pm 4.2$ & $25.6 \pm 5.8$ & 3 & CB-86 & $62.9 \pm 3.6$ & $17.4 \pm 3.0$ & 3.6 \\
\hline CB-49 & $41.1 \pm 3.4$ & $19.8 \pm 5.0$ & 2.1 & CB-87 & $27.1 \pm 2.5$ & $21.2 \pm 2.4$ & 1.3 \\
\hline CB-50 & $57.3 \pm 3.2$ & $14.4 \pm 3.6$ & 4 & & & & \\
\hline
\end{tabular}

C. baccatum türüne ait biber genotiplerinde ölçülen meyve boyu, meyve eni ve meyve şekil indeksi değerlerine ait sonuçlar Çizelge 4'de verilmiştir. Meyve boyu yönünden elde edilen sonuçlar, $C$. baccatum türüne ait biber genotipleri arasında yaklaşık 8.7 (13.4-116.8 $\mathrm{mm}$ ) kat oranında yüksek düzeyde belirgin bir varyasyonun olduğunu göstermiştir. $C$. baccatum biber genotiplerinde ortalama meyve eni değerleri, $6.3 \mathrm{~mm}$ (CB-12)-26.3 mm (CB-46) arasında ölçülmüştür (Çizelge 4). Jarret (2007), C. baccatum türünde genotipler arasında ortalama meyve uzunluğunun $0.8 \mathrm{~cm}$ ile 16.0 $\mathrm{cm}$ ve ortalama meyve genişliğinin $0.5 \mathrm{~cm}$ ile $4.75 \mathrm{~cm}$ aralığında değiştiğini bildirmiştir. Costa ve ark. (2015), C. baccatum türünde ortalama meyve uzunluğunun $8 \mathrm{~cm}$ ve 
ortalama meyve genişliğinin ise $2.5 \mathrm{~cm}$ olduğunu tespit etmişlerdir. Patel ve ark. (2016), C. baccatum genotiplerinde meyve boyunun $33 \mathrm{~mm}-122 \mathrm{~mm}$ arasında ve meyve genişliğinin ise $13 \mathrm{~mm}-28 \mathrm{~mm}$ arasında değiştiğini bildirmişlerdir. Araştırma sonuçları, genotiplere göre değişmekle birlikte meyve boyu ve meyve eni değerleri yönünden belirtilen literatürler ile genel olarak benzerlik göstermiştir. Bu çalışmada, biber genotiplerinin meyve boyları ve meyve enleri oranlanarak meyve şekil indekslerine ait değerler hesaplanmıştır (Çizelge 4). CB-21 genotipinin en yüksek meyve şekil indeksine (10.8) sahip olduğu belirlenmiştir. Bunu, CB-28 (6.8), CB-22 genotipi (6.7) ve CB-52 genotipi (6.7) izlemiştir. En düşük meyve şekil indeksine sahip biber genotipleri CB-27 (0.8) ve CB-69 (0.8) olarak belirlenmiştir. Bu sonuçlar, $C$. baccatum türünde meyve şekli yönünden belirgin farklılıkların olduğunu göstermiştir.

Çizelge 5. C. baccatum biber genotiplerinin bazı meyve özellikleri

Table 5. Some fruit traits of $C$. baccatum genotypes

\begin{tabular}{|c|c|c|c|c|c|c|c|}
\hline \multirow{2}{*}{$\begin{array}{c}\text { Genotip } \\
\text { No }\end{array}$} & \multicolumn{3}{|c|}{ Meyve } & \multirow{2}{*}{$\begin{array}{c}\text { Genotip } \\
\text { No }\end{array}$} & \multicolumn{3}{|c|}{ Meyve } \\
\hline & Rengi & Şekli & Sap Uzunluğu (mm) & & Rengi & Şekli & Sap Uzunluğu (mm) \\
\hline CB-1 & Sarı & Yuvarlak & $25.5 \pm 3.9$ & CB-51 & Yeşil & Üçgen & $37.8 \pm 6.3$ \\
\hline CB-2 & Koyu yeşil & Üçgen & $23.1 \pm 5.0$ & CB-52 & Yeşil & Üçgen & $42.1 \pm 6.1$ \\
\hline CB-3 & Açık yeşil & Üçgen & $41.5 \pm 7.1$ & CB-53 & Açık yeşil & Üçgen & $40.0 \pm 10.0$ \\
\hline CB-4 & Yeşil & Üçgen & $24.9 \pm 4.6$ & CB-55 & Yeşil & Üçgen & $23.0 \pm 4.2$ \\
\hline CB-6 & Açık yeşil & Üçgen & $34.4 \pm 8.1$ & CB-56 & Açık yeşil & Üçgen & $34.4 \pm 5.8$ \\
\hline CB-11 & Yeşil & Üçgen & $29.7 \pm 3.9$ & CB-57 & Yeşil & Üçgen & $40.5 \pm 6.1$ \\
\hline CB-12 & Yeşil & Kalp & $18.5 \pm 3.8$ & CB-58 & Yeşil & Üçgen & $40.4 \pm 9.3$ \\
\hline CB-16 & Yeşil & Yuvarlak & $71.1 \pm 3.1$ & CB-59 & Koyu yeşil & Üçgen & $29.8 \pm 7.6$ \\
\hline CB-17 & Açık yeşil & Üçgen & $33.6 \pm 4.2$ & CB-60 & Yeşil & Üçgen & $40.8 \pm 7.6$ \\
\hline CB-18 & Yeşil & Üçgen & $23.4 \pm 5.8$ & CB-61 & Yeşil & Üçgen & $39.0 \pm 8.8$ \\
\hline CB-20 & Yeşil & Yuvarlak & $27.2 \pm 6.8$ & CB-62 & Yeşil & Yuvarlak & $38.7 \pm 7.6$ \\
\hline CB-21 & Yeşil & Üçgen & $36.0 \pm 4.4$ & CB-63 & Yeşil & Üçgen & $40.0 \pm 10.3$ \\
\hline CB-22 & Açık yeşil & Üçgen & $52.6 \pm 11.6$ & CB-64 & Yeşil & Boynuz & $51.6 \pm 12.5$ \\
\hline CB-23 & Yeşil & Üçgen & $34.4 \pm 4.8$ & CB-65 & Koyu yeşil & Kalp & $36.9 \pm 5.7$ \\
\hline CB-27 & Yeşil & Çan & $39.6 \pm 7.2$ & CB-66 & Yeşil & Kalp & $30.1 \pm 7.9$ \\
\hline CB-28 & Açık yeşil & Boynuz & $46.4 \pm 8.3$ & CB-67 & Yeşil & Yuvarlak & $29.4 \pm 8.7$ \\
\hline CB-29 & Açık yeşil & Üçgen & $46.4 \pm 10.2$ & CB-68 & Yeşil & Üçgen & $38.7 \pm 6.9$ \\
\hline CB-31 & Açık yeşil & Üçgen & $36.0 \pm 4.2$ & CB-69 & Yeşil & Yuvarlak & $38.3 \pm 9.2$ \\
\hline CB-33 & Yeşil & Üçgen & $39.7 \pm 6.5$ & CB-70 & Yeşil & Kare & $32.6 \pm 11.4$ \\
\hline CB-34 & Yeşil & Kalp & $32.4 \pm 5.2$ & CB-71 & Yeşil & Üçgen & $34.3 \pm 5.8$ \\
\hline CB-36 & Yeşil & Üçgen & $44.3 \pm 8.7$ & CB-72 & Açık yeşil & Üçgen & $34.7 \pm 8.7$ \\
\hline CB-37 & Sarı & Üçgen & $38.0 \pm 7.9$ & CB-73 & Açık yeşil & Üçgen & $28.2 \pm 5.5$ \\
\hline CB-38 & Yeşil & Üçgen & $41.6 \pm 5.9$ & CB-74 & Yeşil & Kalp & $39.3 \pm 11.9$ \\
\hline CB-39 & Yeşil & Üçgen & $42.6 \pm 4.7$ & CB-75 & Koyu yeşil & Üçgen & $48.6 \pm 7.7$ \\
\hline CB-40 & Yeşil & Üçgen & $19.1 \pm 2.8$ & CB-76 & Yeşil & Kalp & $40.2 \pm 7.1$ \\
\hline CB-41 & Yeşil & Üçgen & $41.3 \pm 10.7$ & CB-77 & Koyu yeşil & Üçgen & $45.8 \pm 8.5$ \\
\hline CB-42 & Yeşil & Üçgen & $39.7 \pm 5.6$ & CB-78 & Yeşil & Üçgen & $40.9 \pm 6.3$ \\
\hline CB-44 & Yeşil & Üçgen & $39.3 \pm 5.8$ & CB-82 & Koyu yeşil & Üçgen & $44.0 \pm 7.6$ \\
\hline CB-45 & Yeşil & Üçgen & $39.8 \pm 7.1$ & CB-83 & Açık yeşil & Yuvarlak & $37.1 \pm 5.9$ \\
\hline CB-46 & Yeşil & Kalp & $42.3 \pm 8.2$ & CB-84 & Yeşil & Üçgen & $39.8 \pm 7.3$ \\
\hline CB-47 & Yeşil & Kalp & $42.2 \pm 9.4$ & CB-85 & Koyu yeşil & Üçgen & $41.4 \pm 6.9$ \\
\hline CB-48 & Yeşil & Üçgen & $37.3 \pm 5.5$ & CB-86 & Koyu yeşil & Üçgen & $41.3 \pm 5.6$ \\
\hline CB-49 & Yeşil & Kalp & $41.2 \pm 5.8$ & CB-87 & Yeşil & Yuvarlak & $39.6 \pm 6.7$ \\
\hline CB-50 & Yeşil & Üçgen & $36.0 \pm 6.7$ & & & & \\
\hline
\end{tabular}

C. baccatum türüne ait biber genotiplerinin meyve duruşu yönünden \%53.8'inin sarkık, \%32.8'inin yarı dik ve \%13.4'ünün dik olduğu tespit edilmiştir (Çizelge 5). $C$. baccatum biber popülasyonlarının meyve şekli yönünden \%68.7'sinin üçgen, \%13.4'ünün kalp, \%11.9'unun yuvarlak, \%3.0'ünün boynuz, \%1.5'inin kare ve \%1.5'inin ise çan meyve şekline sahip oldukları belirlenmiştir (Çizelge 5). Meyve uç şekli yönünden ise biber genotiplerinin \%64.2'sinin sivri, \%16.5'inin hafif basık, \%9.0'unun yuvarlak, \%6.0'sının basık, \%2.9'unun çok basık ve \%1.4'ünün ise çok sivri yapıda olduğu saptanmıştır. Araştırmada, biber genotiplerinin 
\%88.0'inde sap çukurunun hiç oluşmadığı belirlenmiştir (Çizelge 5). Günümüzde biber çeşit ıslahında, tüketicilerin talepleri doğrultusunda farklı meyve özelliklerine sahip ürün segmentleri oluşmuş ve yeni biber çeşitleri geliştirilmiştir. Luitel ve ark. (2018), C. chinense türüne ait 47 genotipten \% 38.3'ünün konik şekilli meyvelere sahip olduğunu ve olgun meyve renginin ağırlıklı olarak kırmızı (\% 51.1), turuncu (\% 21.3) ve sarı (\% 14.9) renk tonlarında olduğunu bildirmişlerdir. Taş (2020), C. chinense türüne ait 75 genotipin \%10.7'sinin yassı,\%5.4'ünün yuvarlak, \%14.6'sının kalp şekli, \%6.6'sının kare, \%8'inin ikizgen yamuk üçgen, $\% 32$ 'sinin üçgen, \%10.7'sinin dar üçgen ve \%6.6'sının boynuz şeklinde meyvelere sahip olduğunu belirlemiştir. Biber çeşitlerinde meyve sap uzunluğunun kısa olması üreticiler ve tüketiciler tarafından istenen özelliklerden birisidir. Araştırma sonucunda, $C$. baccatum türüne ait biber genotiplerinde meyve sap uzunluklarının $18.5 \mathrm{~mm}$ $71.1 \mathrm{~mm}$ arasında değiştiği tespit edilmiştir (Çizelge 5). Taş (2020), C. chinense türüne ait biber genotiplerinde meyve sap uzunluklarının, $19.9 \mathrm{~mm}-61.9 \mathrm{~mm}$ arasında değiştiğini bildirmiştir.

C. baccatum türüne ait biber genotiplerinde, meyve kabukları yönünden yapılan görsel incelemede renk tonları yönünden belirgin farklılıkların olduğu tespit edilmiştir (Çizelge 5). Araştırmada, C. baccatum biber genotiplerinin; \%67.1'inin yeşil, \%17.9'unun açık yeşil, \%11.9'unun koyu yeşil ve \%3.1'inin ise sarı renk tonlarında oldukları belirlenmiştir (Çizelge 5). Jarret (2007), USDA/ARS biber germplasm koleksiyonunda 295 tane $C$. baccatum biber türüne ait genotipte olgun meyve renklerinin kırmızı (\% 73.6), turuncu (\% 19.7), sarı (\% 3), yeşil (\% 0.3) ve karışık (\% 3) renk tonlarında olduğunu bildirmiştir. $C$. baccatum meyvelerinde renk yönünden tespit edilen bu farklılıklar, $C$. chinense türünde yapılan çalışmalarla da benzerlik göstermiştir. Luitel ve ark. (2018), C. chinense türüne ait 47 biber genotipinde meyve rengi yönünden \%51.0'inin kırmızı, \%21.3'ünün turuncu ve \%14.9'unun sarı renkli olduğunu tespit etmişlerdir. Taş (2020), C. chinense türüne ait biber genotiplerinde; \%25.4'ünün koyu yeşil, \%40.0'ının yeşil, \%24.0'ünün açık yeşil, \%8.0'inin sarı ve \%2.6 'sının ise açık sarı renk tonlarında meyve rengine sahip olduklarını belirlemiştir. Araştırma sonuçları, C. baccatum türüne ait biber genotiplerinin meyve verim potansiyelleri yönünden geniş bir varyabilite gösterdiğini ortaya koymuştur (Çizelge 6). C. baccatum biber genotiplerinde meyve sayıları, ortalama 50.6 adet-1268.7 adet arasında değişim göstermiştir En yüksek meyve sayısı, CB-49 genotipinde ortalama 1268.7 adet olarak bulunmuştur. Bunu sırasıyla, CB-47 (1072.7 adet) ve CB-40 (855.2 adet) genotipleri izlemiştir (Çizelge 6). En az meyve sayısının 50.6 adet ile CB-2 genotipinde olduğu saptanmıştır. $C$. baccatum türüne ait biber genotipleri ortalama meyve ağırlığı değerleri yönünden, 0.3 g-14.9 g arasında değişim göstermiştir. En yüksek ortalama meyve ağırlığı değerleri sırasıyla; CB-2 (14.9 g), CB-36 (9.5 g) ve CB-77 (9.3 g) genotiplerinde belirlenmiştir (Çizelge 6 ).

Jarret (2007), C. baccatum türüne ait biber genotiplerinin ortalama meyve ağırlığının $0.15 \mathrm{~g}-22.8 \mathrm{~g}$ aralığında değişim gösterdiğini bildirmiştir. En yüksek değerler; CB47 (7517.2 g) ve CB-49 (7414.9 g) genotiplerinde olduğu belirlenmiştir (Çizelge 6). En düşük verim değerleri ise CB-4 (171.0 g), CB-12 (183.3 g) ve CB-55 (240.7 g) genotiplerinde tespit edilmiştir. Cherian ve Indira (2003), C. chinense türüne ait biber genotiplerinde bitki başına meyve sayısının ortalama 4.0-63.5 adet ve bitki başına verim değerinin ise $12.0 \mathrm{~g}-185.0 \mathrm{~g}$ arasında değişim gösterdiğini tespit etmişlerdir. Yaldız ve Özgüven (2011), C. frutescens türünde meyve sayısı değerlerinin 2.0370.7 adet/bitki arasında dağılış gösterdiğini bildirmiştir. En yüksek toplam meyve sayısı HC (370.7 adet/bitki) hatlarından elde edilmiştir. Mavi ve Mavi (2015); bazı süs biberi genotipleri incelendiğinde, ortalama bitki başına meyve sayısının 11 ile 63 adet arasında dağılış gösterdiğini belirlemişlerdir.

Morfolojik varyasyonların bitki ıslahı çalışmalarında büyük bir önemi vardır (Balkaya ve ark., 2010). Çünkü yetiştirilen türler içerisinde gen havuzlarında bulunan mevcut varyasyonların bilinmesi ve bunların ıslah programlarına uygulanması ıslah çalışmasında başarıyı artıran temel unsurlardır (Bliss, 1981). Temel bileşen analizi (TBA), sebze ıslahında çok boyutlu alan içinde genotipler arasındaki ilişkiyi en iyi temsil edebilecek bir eksen ya da eksenler dizisi üzerindeki genotip izdüşümlerinin görüntülenmesi şeklinde gerçekleştirilmektedir (Balkaya ve ark., 2010; Karaağaç, 2013). Bu analiz yöntemi ile karşılıklı etkileşim halinde bulunan çok sayıda değişkene ait verilerin boyutları indirgenerek daha kolay yorumlanabilir hale getirilmesi mümkün olmaktadır (Karaağaç, 2013).

Araştırmada, temel bileşen analizi sonucunda $C$. baccatum biber genotiplerinde birbirinden bağımsız 10 adet temel bileşen eksen elde edilmiştir (Çizelge 7). Temel bileşen analiz sonuçlarına göre, $C$. baccatum biber popülasyonunda toplam varyasyonun $\% 75.75$ oranında olduğu tespit edilmiştir (Çizelge 7). Literatürlerde, TBA analizinde eigen değerleri 1'den büyük olan temel bileşen eksenlerinin oldukça güvenilir olduğu bildirilmiştir (Özdamar, 2004; Balkaya ve ark., 2010; Karaağaç, 2013). 
Çizelge 6. Capsicum baccatum biber genotiplerinde verim unsurlarına ait sonuçlar Table 6. The yield components results of $C$. baccatum genotypes

\begin{tabular}{|c|c|c|c|c|c|c|c|}
\hline $\begin{array}{c}\text { Genotip } \\
\text { No }\end{array}$ & $\begin{array}{c}\text { Meyve Sayısı/ Bitki } \\
\text { (adet) }\end{array}$ & $\begin{array}{c}\text { Ortalama Meyve } \\
\text { Ağırlığı (g) }\end{array}$ & $\begin{array}{l}\text { Toplam Meyve } \\
\text { Ağırlığı/Bitki(g) }\end{array}$ & $\begin{array}{c}\text { Genotip } \\
\text { No }\end{array}$ & $\begin{array}{c}\text { Meyve Sayısı/ Bitki } \\
\text { (adet) }\end{array}$ & $\begin{array}{c}\text { Ortalama Meyve } \\
\text { Ağırlığı (g) }\end{array}$ & $\begin{array}{l}\text { Toplam Meyve } \\
\text { Ağırlığı/Bitki(g) }\end{array}$ \\
\hline CB-1 & $368.1 \pm 45.3$ & $0.7 \pm 0.1$ & $543.1 \pm 24.2$ & CB-51 & $347.2 \pm 22.7$ & $2.8 \pm 0.2$ & $964.3 \pm 32.4$ \\
\hline CB-2 & $50.6 \pm 16.2$ & $14.9 \pm 1.2$ & $752.4 \pm 26.1$ & CB-52 & $519.9 \pm 43.6$ & $3.6 \pm 0.0$ & $1884.0 \pm 45.8$ \\
\hline CB-3 & $166.3 \pm 14.9$ & $3.7 \pm 0.4$ & $618.7 \pm 33.1$ & CB-53 & $102.2 \pm 29.1$ & $8.1 \pm 0.4$ & $821.4 \pm 31.1$ \\
\hline CB-4 & $349.4 \pm 42.5$ & $0.4 \pm 0.0$ & $171.0 \pm 10.1$ & CB-55 & $114.3 \pm 37.1$ & $3.8 \pm 0.4$ & $240.7 \pm 28.5$ \\
\hline CB-6 & $199.6 \pm 18.7$ & $3.7 \pm 1.7$ & $752.3 \pm 23.7$ & CB-56 & $256.2 \pm 38.7$ & $3.0 \pm 0.3$ & $768.5 \pm 36.4$ \\
\hline CB-11 & $466.5 \pm 52.4$ & $0.8 \pm 0.1$ & $346.5 \pm 29.4$ & CB-57 & $135.4 \pm 37.2$ & $3.3 \pm 0.8$ & $449.9 \pm 35.0$ \\
\hline CB-12 & $518.2 \pm 40.8$ & $0.3 \pm 0.3$ & $183.3 \pm 15.8$ & CB-58 & $72.2 \pm 19.6$ & $6.8 \pm 0.9$ & $486.6 \pm 34.8$ \\
\hline CB-16 & $688.4 \pm 23.9$ & $1.0 \pm 0.1$ & $743.8 \pm 33.3$ & CB-59 & $193.2 \pm 34.7$ & $2.2 \pm 0.9$ & $399.1 \pm 22.7$ \\
\hline CB-17 & $356.6 \pm 15.9$ & $2.6 \pm 0.1$ & $931.7 \pm 31.9$ & CB-60 & $55.2 \pm 12.3$ & $8.0 \pm 0.9$ & $440.5 \pm 26.9$ \\
\hline CB-18 & $422.1 \pm 48.4$ & $1.4 \pm 0.1$ & $626.3 \pm 32.3$ & CB-61 & $64.2 \pm 11.2$ & $2.1 \pm 1.2$ & $333.2 \pm 20.7$ \\
\hline CB-20 & $497.3 \pm 23.0$ & $1.7 \pm 0.0$ & $871.2 \pm 34.8$ & CB-62 & $78.2 \pm 12.6$ & $4.9 \pm 0.5$ & $401.4 \pm 12.7$ \\
\hline CB-21 & $584.4 \pm 21.7$ & $2.3 \pm 0.2$ & $1349.7 \pm 41.6$ & CB-63 & $126.1 \pm 77.0$ & $5.9 \pm 2.0$ & $681.5 \pm 29.5$ \\
\hline CB-22 & $181.6 \pm 15.2$ & $6.6 \pm 1.0$ & $1184.3 \pm 44.7$ & CB-64 & $101.0 \pm 21.1$ & $8.5 \pm 0.4$ & $854.7 \pm 23.2$ \\
\hline CB-23 & $532.7 \pm 67.2$ & $2.3 \pm 0.2$ & $1222.8 \pm 43.9$ & CB-65 & $219.2 \pm 23.1$ & $5.0 \pm 0.2$ & $751.6 \pm 26.2$ \\
\hline CB-27 & $149.9 \pm 27.6$ & $1.7 \pm 1.2$ & $1372.5 \pm 54.2$ & CB-66 & $55.3 \pm 9.3$ & $3.4 \pm 0.7$ & $1006.3 \pm 44.2$ \\
\hline CB-28 & $150.3 \pm 53.5$ & $6.5 \pm 0.8$ & $974.0 \pm 34.1$ & CB-67 & $208.1 \pm 53.4$ & $4.4 \pm 0.1$ & $925.7 \pm 34.1$ \\
\hline CB-29 & $115.1 \pm 23.8$ & $9.1 \pm 0.9$ & $1037.6 \pm 40.3$ & CB-68 & $144.2 \pm 18.9$ & $5.3 \pm 0.8$ & $761.3 \pm 37.5$ \\
\hline CB-31 & $274.2 \pm 33.6$ & $3.2 \pm 0.6$ & $859.2 \pm 34.9$ & CB-69 & $318.2 \pm 20.0$ & $3.9 \pm 0.9$ & $1254.1 \pm 35.2$ \\
\hline CB-33 & $185.4 \pm 20.3$ & $6.5 \pm 0.3$ & $1193.4 \pm 59.0$ & CB-70 & $164.1 \pm 13.6$ & $4.5 \pm 0.5$ & $904.2 \pm 39.9$ \\
\hline CB-34 & $179.1 \pm 55.2$ & $5.7 \pm 0.6$ & $1000.4 \pm 30.2$ & CB-71 & $366.1 \pm 20.0$ & $1.9 \pm 0.5$ & $691.0 \pm 33.3$ \\
\hline CB-36 & $208.3 \pm 49.3$ & $9.5 \pm 1.8$ & $1417.1 \pm 34.5$ & CB-72 & $428.3 \pm 95.4$ & $1.5 \pm 0.0$ & $633.1 \pm 29.2$ \\
\hline CB-37 & $214.4 \pm 35.9$ & $7.2 \pm 0.9$ & $1195.3 \pm 31.4$ & CB-73 & $338.3 \pm 45.0$ & $2.5 \pm 0.2$ & $853.5 \pm 29.7$ \\
\hline CB-38 & $264.0 \pm 20.9$ & $4.1 \pm 1.0$ & $1091.3 \pm 27.8$ & CB-74 & $216.3 \pm 75.4$ & $4.5 \pm 0.2$ & $972.7 \pm 22.3$ \\
\hline CB-39 & $228.7 \pm 42.5$ & $7.7 \pm 0.4$ & $1753.2 \pm 27.3$ & CB-75 & $129.4 \pm 23.4$ & $8.1 \pm 0.5$ & $1046.7 \pm 37.9$ \\
\hline CB-40 & $855.2 \pm 31.4$ & $0.5 \pm 0.0$ & $480.8 \pm 31.1$ & CB-76 & $225.2 \pm 69.6$ & $4.3 \pm 1.4$ & $980.3 \pm 35.5$ \\
\hline CB-41 & $404.5 \pm 20.4$ & $3.2 \pm 0.4$ & $1297.8 \pm 28.2$ & CB-77 & $111.2 \pm 17.6$ & $9.3 \pm 1.5$ & $1035.1 \pm 26.1$ \\
\hline CB-42 & $449.4 \pm 22.7$ & $1.5 \pm 0.0$ & $690.1 \pm 37.2$ & CB-78 & $248.4 \pm 60.7$ & $5.1 \pm 0.1$ & $1277.7 \pm 37.3$ \\
\hline CB-44 & $289.7 \pm 23.9$ & $5.4 \pm 0.7$ & $1514.0 \pm 41.3$ & CB-82 & $223.7 \pm 68.0$ & $3.9 \pm 0.2$ & $866.6 \pm 27.4$ \\
\hline CB-45 & $198.2 \pm 19.9$ & $7.6 \pm 0.3$ & $1508.8 \pm 38.6$ & CB-83 & $308.3 \pm 50.4$ & $3.2 \pm 0.3$ & $967.6 \pm 26.1$ \\
\hline CB-46 & $212.2 \pm 23.7$ & $7.6 \pm 0.6$ & $1613.7 \pm 36.7$ & CB-84 & $460.2 \pm 46.1$ & $2.5 \pm 0.0$ & $1150.4 \pm 39.7$ \\
\hline CB-47 & $1072.7 \pm 56.9$ & $7.0 \pm 1.1$ & $7517.2 \pm 48.7$ & CB-85 & $289.2 \pm 88.5$ & $4.2 \pm 1.0$ & $1222.0 \pm 47.9$ \\
\hline CB-48 & $241.4 \pm 37.8$ & $5.4 \pm 1.7$ & $1364.3 \pm 43.9$ & CB-86 & $247.2 \pm 84.6$ & $5.6 \pm 0.6$ & $1364.5 \pm 47.7$ \\
\hline CB-49 & $1268.7 \pm 61.6$ & $6.3 \pm 1.8$ & $7414.9 \pm 46.6$ & CB-87 & $470.3 \pm 57.2$ & $3.2 \pm 0.3$ & $1497.7 \pm 48.3$ \\
\hline CB-50 & $357.8 \pm 38.5$ & $5.9 \pm 0.4$ & $1351.2 \pm 45.6$ & & & & \\
\hline
\end{tabular}

Çalışmada, ilk 10 temel bileşenin eigen değerlerine ait katsayıların, 1.03-5.13 arasında değiştiği bulunmuştur (Çizelge 7). Temel bileşen eksenin değerleri incelendiğinde; ilk temel bileşen eksenin toplam varyasyon değerinin $\% 17.68^{\prime}$ ini, ikinci temel bileşen eksenin varyasyonun $\% 12.08$ 'ini ve üçüncü temel eksenin ise toplam varyasyonun \%8.61'ini açıkladığı belirlenmiştir. Çalışmada, temel bileşen analizinde incelenen kriterler yönünden bileşenlerdeki ağırlık katsayı değerlerinin 0.3 ve üzeri olduğu takdirde önemli ağırlığa sahip oldukları kabul edilmiştir (Brown, 1991). Temel bileşen analizinde toplam varyasyonun \%17.68'ini kapsayan TB-1 ekseninde 0.3 ve üzerinde yüksek katsayılara sahip olan özelliklerin sırasıyla meyve duruşu $(-0.42)$, meyve eni $(-0.77)$, ortalama meyve ağırlığı (0.79 ), bitki başına meyve sayısı (0.81), meyve yaş ağırlığı
(-0.89) ve meyve kuru ağırlığı (-0.79) özellikleri olduğu saptanmıştır (Çizelge 7). C. baccatum türüne ait biber genotiplerinde temel bileşen analizinde TB-2 ekseni toplam varyasyonun \% 12.08'ini oluşturmuştur. TB-2 ekseninde; bitki duruşu (-0.75), bitki boyu (0.82), gövde çapı (0.73), meyve sap uzunluğu (0.33) ve bitki başına meyve ağırlığı (0.38) özellikleri önemli olduğu belirlenmiştir (Çizelge 7).

Capsicum türüne ait birçok türde popülasyonların mevcut varyasyon düzeylerinin belirlenmesine yönelik bazı çalışmalar yapılmıştır. Luitel ve ark. (2018), C. chinense türüne ait 47 biber genotip arasında yapılan temel bileşen analizi sonucunda ilk iki eksende toplam varyasyonun $\% 89.42$ oranında olduğunu belirlemişlerdir. Taş (2020), 75 adet $C$. chinense biber popülasyonunda ilk altı temel bileşen ekseninin toplam varyasyonun 
\%70.99'unu açıkladığını bildirmiştir. Agyare ve ark. (2016), Gana orijinli ait yerel 50 adet C. annuum genotipinin toplam varyasyon oranının \%59.61 oranında olduğunu saptamışlardır. Velazquez Ventura ve ark. (2018), C. annuum ve $C$. frutescens L. türlerine ait 131 adet biber genotipinde \%65.2 oranında varyasyona sahip olduğunu bildirmişlerdir. Castro ve Davila (2008), 11 farklı ülkeden toplanan ve dört biber türünü temsil eden (C. annuum, C. baccatum, C. chinense, C. frutescens) 93 biber genotipin toplam varyasyon düzeyinin $\% 78$ düzeyinde olduğunu bildirmişlerdir. Villota Ceron (2012), 68 yerel Capsicum spp. popülasyonunda toplam varyasyonun \%70.8'ini oluşturduğunu bildirmişlerdir. Araştırma sonuçları, belirlenen varyasyon düzeyinin literatürler ile genel olarak uyumlu olduğunu göstermiştir. Ayrıca elde edilen bu sonuçlar, C. baccatum popülasyonunun heterojen bir gen havuzuna sahip olduğunu ortaya koymuştur.

Çizelge 7. C. baccatum biber popülasyonlarında incelenen özelliklerin temel bileşen analizine göre faktör grupları ve bunlara karşılık gelen temel bileşen eksenleri

Table 7. Principal component (PC) axes and coefficients of each plant traits in C. baccatum populations

Temel bileşen eksenleri

\begin{tabular}{|c|c|c|c|c|c|c|c|c|c|c|}
\hline Eigen değeri (Özdeğer) & 5.13 & 3.50 & 2.50 & 2.33 & 1.96 & 1.67 & 1.43 & 1.26 & 1.16 & 1.03 \\
\hline Varyasyon. \% & 17.68 & 12.08 & 8.61 & 8.02 & 6.77 & 5.75 & 4.93 & 4.34 & 4.01 & 3.56 \\
\hline Kümülatif varyasyon. \% & 17.68 & 29.76 & 38.37 & 46.39 & 53.17 & 58.92 & 63.85 & 68.18 & 72.19 & 75.75 \\
\hline
\end{tabular}

Faktör katsayıları

\begin{tabular}{|c|c|c|c|c|c|c|c|c|c|c|}
\hline Özellikler & TB1 & TB2 & TB3 & TB4 & TB5 & TB6 & TB7 & TB8 & TB9 & TB10 \\
\hline Bitki duruşu & 0.27 & -0.75 & -0.05 & 0.26 & 0.01 & -0.13 & -0.15 & -0.11 & 0.03 & -0.16 \\
\hline Bitki boyu (cm) & -0.11 & 0.82 & 0.17 & -0.13 & 0.04 & 0.04 & -0.08 & -0.26 & -0.11 & -0.04 \\
\hline Gövde çapı (mm) & 0.07 & 0.73 & -0.09 & 0.16 & 0.15 & 0.03 & -0.17 & -0.31 & 0.05 & -0.17 \\
\hline Yaprak boyu $(\mathrm{cm})$ & 0.00 & 0.08 & 0.00 & 0.08 & 0.19 & 0.12 & -0.01 & -0.88 & 0.00 & -0.03 \\
\hline Yaprak eni (cm) & -0.03 & 0.26 & -0.04 & -0.09 & 0.05 & 0.02 & 0.11 & -0.83 & 0.08 & -0.10 \\
\hline Yaprak rengi & 0.14 & 0.14 & -0.05 & -0.11 & 0.12 & -0.10 & 0.01 & 0.19 & -0.79 & -0.03 \\
\hline Yaprak şekli & -0.06 & 0.11 & -0.14 & -0.20 & -0.07 & 0.02 & 0.57 & 0.39 & 0.36 & -0.04 \\
\hline Meyve duruşu & -0.42 & -0.02 & 0.71 & -0.15 & -0.06 & 0.21 & -0.03 & -0.04 & -0.01 & 0.04 \\
\hline Meyve eni (mm) & -0.77 & 0.15 & -0.36 & 0.05 & 0.03 & 0.21 & -0.08 & -0.28 & -0.01 & -0.13 \\
\hline Meyve boyu (mm) & -0.28 & 0.28 & 0.70 & 0.13 & -0.08 & -0.27 & 0.22 & 0.06 & 0.09 & 0.05 \\
\hline Meyve sap uzunluğu(mm) & -0.15 & 0.33 & 0.32 & 0.25 & -0.17 & -0.04 & 0.10 & -0.02 & -0.30 & -0.46 \\
\hline Meyve sap çukuru & -0.13 & -0.04 & -0.34 & -0.10 & 0.04 & 0.02 & -0.14 & -0.06 & 0.02 & -0.75 \\
\hline Meyve rengi & -0.20 & -0.24 & -0.14 & -0.41 & -0.15 & -0.14 & 0.05 & -0.19 & -0.46 & 0.12 \\
\hline Meyve şekli & -0.27 & 0.15 & 0.12 & -0.08 & -0.06 & 0.69 & -0.01 & 0.05 & 0.18 & 0.09 \\
\hline Meyve uç şekli & 0.01 & -0.01 & -0.90 & 0.18 & 0.09 & -0.08 & -0.09 & -0.03 & -0.03 & -0.08 \\
\hline Gövdede antosiyanin yoğunluğu & 0.02 & -0.08 & -0.23 & -0.10 & -0.25 & -0.03 & -0.66 & 0.22 & 0.07 & -0.19 \\
\hline Gövdede antosiyanin oluşumu & -0.01 & -0.16 & 0.10 & -0.02 & 0.09 & 0.05 & 0.81 & -0.08 & -0.07 & -0.04 \\
\hline Çiçek rengi & 0.03 & 0.08 & -0.17 & -0.48 & -0.07 & -0.29 & -0.08 & 0.16 & 0.29 & 0.34 \\
\hline Yaprak rengi L değeri & -0.07 & -0.08 & 0.10 & 0.01 & -0.91 & 0.01 & -0.10 & 0.18 & 0.03 & 0.08 \\
\hline Yaprak rengi a değeri & -0.18 & -0.03 & -0.18 & 0.16 & -0.30 & -0.26 & 0.13 & -0.36 & 0.15 & 0.21 \\
\hline Yaprak rengi b değeri & 0.03 & -0.03 & 0.10 & -0.03 & -0.92 & 0.14 & -0.14 & 0.03 & 0.04 & -0.07 \\
\hline Meyve rengi L değeri & -0.06 & -0.10 & -0.11 & 0.86 & 0.04 & -0.23 & -0.11 & 0.04 & 0.08 & 0.05 \\
\hline Meyve rengi a değeri & 0.06 & 0.02 & -0.13 & 0.20 & -0.20 & 0.60 & 0.21 & -0.39 & 0.01 & -0.13 \\
\hline Meyve rengi b değeri & 0.18 & -0.06 & -0.19 & 0.86 & -0.09 & 0.17 & 0.07 & -0.12 & 0.12 & 0.07 \\
\hline Ortalama meyve ağırlığı (g) & -0.79 & 0.15 & 0.29 & -0.06 & -0.06 & -0.16 & 0.09 & -0.01 & 0.11 & -0.07 \\
\hline Bitki başına meyve sayısı & 0.81 & 0.02 & -0.22 & -0.10 & 0.09 & -0.14 & 0.03 & -0.10 & 0.12 & -0.10 \\
\hline Bitki başına meyve ağırlığı & -0.28 & 0.38 & 0.17 & 0.09 & 0.03 & -0.05 & 0.11 & -0.44 & 0.17 & -0.49 \\
\hline Meyve yaş ağırlığı & -0.89 & 0.15 & 0.20 & -0.05 & 0.04 & 0.10 & 0.03 & 0.00 & 0.04 & 0.01 \\
\hline Meyve kuru ağırlığı & -0.79 & -0.04 & -0.04 & -0.17 & 0.01 & -0.04 & 0.07 & -0.07 & 0.10 & -0.32 \\
\hline
\end{tabular}

Cluster (küme) analizi sonucunda $C$. baccatum biber türüne ait genotipler arasında "Gruplararası benzerlik" yöntemine göre elde edilen dendogram Şekil 1'de verilmiştir. Çalışmasında küme analizi sonucunda elde edilen dendrogram incelendiğinde; $C$. baccatum popülasyonunda biber genotiplerinin toplam 8 grup ve 28 alt grup içerisinde dağılış gösterdikleri tespit edilmiştir (Şekil 1). C. baccatum biber popülasyonunda küme analizi sonucunda elde edilen dendogramda toplamda 20 genotip sayısı ve 7 alt grup sayısı ile $F$ grubu en fazla 
genotipin kümelendiği grup olarak tespit edilmiştir.

Grup A: Küme analizinde A grubunun toplam 5 adet genotipten oluştuğu belirlenmiştir. Grup A, 3 alt grup içerisinde kümelenmiştir (Şekil 1). Grup içerisinde genotip sayısı az olmasına rağmen, oldukça heterojen bir gruptur. Meyve şekli yönünden yuvarlak ve üçgen meyve olarak değişkenlik göstermiştir. Yapılan değerlendirme sonucunda, bitki başına meyve sayısının (444 adet), diğer gruplara göre en fazla olan grup olduğu tespit edilmiştir (Çizelge 8).

Grup B: Dendogramda 5 adet $C$. baccatum genotipinden oluşan grup, 2 alt gruptan meydana gelmiştir. Çiçek rengi bakımından en fazla varyasyonun görüldüğü gruptur. $C$. baccatum türüne ait biber genotiplerinin çiçeklerinin beyaz-çizgili, beyaz-sarı renklerinde olduğu belirlenmiştir.

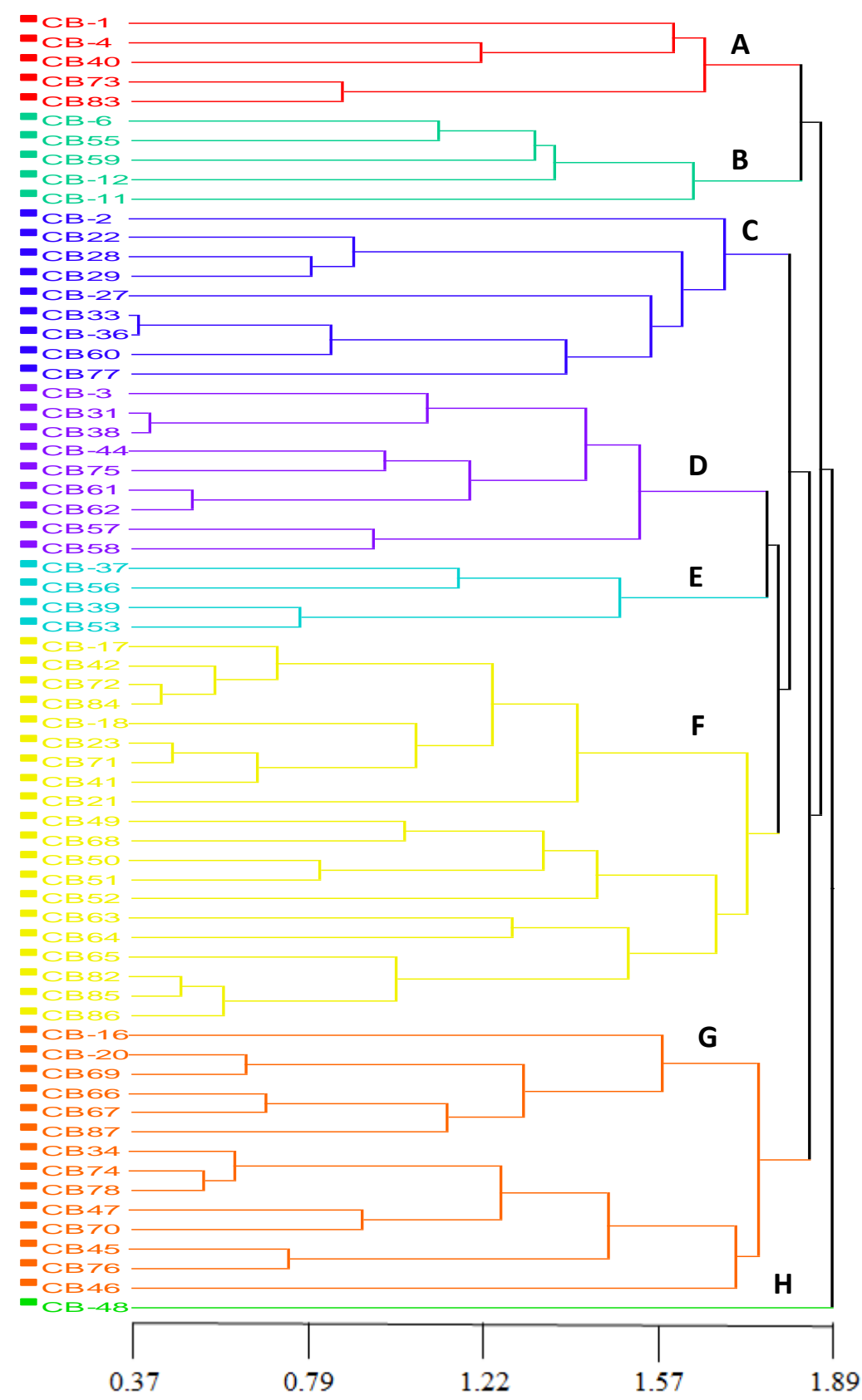

Şekil 1. C. baccatum biber popülasyonlarında küme analizi sonucunda elde edilen gruplar arası benzerlik dendrogramı

Figure 1. Genetic grouping of C. baccatum populations by cluster analysis

Grup C: Bu grup içerisinde 9 adet C. baccatum genotipi yer almıştır. Bu grup, dört alt gruptan oluşmuştur. Bu grup, birçok özellik bakımından diğer gruplara göre daha fazla ön sıralarda yer almıştır (Çizelge 8). Tüm gruplar içerisinde en uzun bitki boyuna $(42.8 \mathrm{~cm})$ sahip grup olarak belirlenmiştir. Ayrıca, genotiplerin ortalama sap uzunluğu değeri (41.3 mm), tüm gruplar içerisinde ilk sırada yer almıştır. Ortalama meyve boyu $(72.7 \mathrm{~mm})$ 
değeri yönünden de tüm gruplar içerisinde ilk sırada olduğu saptanmıştır. Yine ortalama meyve ağırlığının 7.5 g değeri ile diğer gruplardan daha yüksek olduğu bulunmuştur (Çizelge 8).

Grup D: Dendrogramda grup içerisinde 9 genotip bulunmakta olup üç alt gruptan oluşmaktadır. Bu grup içerisindeki genotiplerin çiçeklerinin beyaz-sarı renk tonlarında olduğu tespit edilmiştir (Çizelge 8). Ayrıca grup içerisinde yer alan tüm bitkilerin yarı dik bitki formunda oldukları belirlenmiştir.

Grup E: Bu grup 4 adet genotipten oluşmuştur. Genotipler 2 alt grup içerisinde kümelenmiştir. Genotiplerin ortalama gövde çapı değerinin (13.3 mm), diğer tüm gruplar içerisinde en yüksek değer olduğu belirlenmiştir (Çizelge 8). Bitki duruşu yönünden biber genotiplerinin yarı dik formda olduğu tespit edilmiştir. Grup E'nin meyve şeklinin üçgen yapıda olduğu belirlenmiştir.

Çizelge 8. Küme analizi sonucunda C. baccatum popülasyonlarında aynı gruplarda yer alan genotiplerin özelliklerine ait sonuçlar

Table 8. Mean trait values used in C. baccatum populations group identification by cluster analysis

\begin{tabular}{|c|c|c|c|c|c|c|c|c|}
\hline \multirow[b]{2}{*}{ Özellikler } & \multicolumn{8}{|c|}{ GRUPLAR } \\
\hline & A & B & $\mathbf{C}$ & D & $\mathbf{E}$ & $\mathbf{F}$ & G & $\mathbf{H}$ \\
\hline Bitki boyu (cm) & $27.5 \pm 10.5$ & $36.3 \pm 3.9$ & $42.8 \pm 4.9$ & $31.8 \pm 4.6$ & $36.0 \pm 3.6$ & $40.3 \pm 5.6$ & $38.8 \pm 4.3$ & $37.5 \pm 2.8$ \\
\hline Bitki duruşu & 2,3 & $1,2,3$ & 1 & 2 & 2 & 1,2 & 1,2 & 2 \\
\hline Gövde çapı (mm) & $11.3 \pm 1.8$ & $9.6 \pm 0.9$ & $11.8 \pm 2.1$ & $8.8 \pm 1.3$ & $13.3 \pm 2.0$ & $12.4 \pm 1.6$ & $12.7 \pm 1.4$ & $10.7 \pm 1.1$ \\
\hline Gövdede antosiyanin oluşumu & 1 & 1 & 1 & 1,2 & 1 & 1,2 & 1 & 1 \\
\hline Gövdede antosiyanin yoğunluğu & $2,3,4$ & 4 & $1,2,3,4$ & $1,2,3,4$ & $1,2,3$ & $1,2,3,4$ & $2,3,4$ & 2 \\
\hline Yaprak eni (cm) & $1.9 \pm 0.7$ & $1.0 \pm 0.2$ & $1.3 \pm 0.1$ & $1.8 \pm 0.6$ & $1.4 \pm 0.4$ & $2.2 \pm 0.5$ & $2.2 \pm 0.4$ & $2.5 \pm 0.2$ \\
\hline Yaprak boyu (cm) & $3.8 \pm 0.9$ & $3.3 \pm 0.6$ & $3.7 \pm 0.3$ & $3.5 \pm 0.6$ & $3.2 \pm 0.4$ & $4.4 \pm 0.6$ & $4.2 \pm 0.4$ & $4.8 \pm 0.6$ \\
\hline Yaprak şekli & $1,2,3$ & 2,3 & 2,3 & $1,2,3$ & 1,2 & $1,2,3$ & $1,2,3$ & 2 \\
\hline Yaprak rengi & 2,1 & $1,2,3$ & 1,2 & $1,2,3$ & $1,2,3$ & $1,2,3$ & $1,2,3$ & 1 \\
\hline Yaprak rengi L & $41.4 \pm 2.6$ & $41.8 \pm 1.9$ & $43.9 \pm 1.4$ & $41.8 \pm 1.9$ & $40.0 \pm 3.1$ & $40.2 \pm 1.9$ & $40.4 \pm 2.1$ & $41.6 \pm 1.1$ \\
\hline Yaprak rengi a (-) değeri & $17.1 \pm 1.7$ & $17.1 \pm 1.3$ & $17.4 \pm 0.6$ & $16.7 \pm 1.0$ & $15.2 \pm 2.4$ & $16.5 \pm 1.4$ & $16.6 \pm 1.7$ & $15.7 \pm 3.0$ \\
\hline Yaprak rengi b değeri & $18.0 \pm 2.6$ & $18.1 \pm 2.5$ & $20.2 \pm 1.7$ & $17.9 \pm 1.9$ & $14.8 \pm 3.1$ & $16.8 \pm 2.5$ & $17.2 \pm 2.9$ & $17.3 \pm 2.1$ \\
\hline Çiçek rengi & 1 & $1,2,3$ & 1,2 & 1 & 1 & 1 & 1 & 1 \\
\hline Meyve duruşu & 1 & $1,2,3$ & 2,3 & 2,3 & 1,3 & 2,3 & $1,2,3$ & 2 \\
\hline Meyve eni (mm) & $12.3 \pm 4.6$ & $9.9 \pm 2.9$ & $18.1 \pm 4.7$ & $14.9 \pm 3.3$ & $14.4 \pm 3.5$ & $13.1 \pm 3.9$ & $21.4 \pm 4.9$ & $76.3 \pm 1.2$ \\
\hline Meyve boyu (mm) & $24.4 \pm 13.1$ & $35.7 \pm 10.3$ & $72.7 \pm 26.9$ & $59.2 \pm 11.8$ & $69.8 \pm 8.2$ & $57.7 \pm 19.9$ & $33.6 \pm 10.5$ & $37.3 \pm 6.5$ \\
\hline Meyve sap uzunluğu(mm) & $26.9 \pm 6.5$ & $27.1 \pm 6.2$ & $41.3 \pm 10.1$ & $40.6 \pm 3.4$ & $38.8 \pm 3.4$ & $36.2 \pm 9.5$ & $39.0 \pm 10.5$ & $37.36 \pm 5.3$ \\
\hline Meyve sap çukuru & 1 & 1 & 1 & 1 & 1 & 2 & $1,2,3$ & 2 \\
\hline Meyve şekli & 1,2 & 2,3 & $2,4,5,6$ & 1,2 & 2 & $2,3,4,5$ & $1,2,3,5,6$ & 2 \\
\hline Meyve uç şekli & $3,4,5,6$ & $2,3,4$ & 2 & 2,3 & 2 & $1,2,4$ & $2,3,4,5,6$ & 4 \\
\hline Meyve rengi & $1,2,4$ & $1,2,3$ & $1,2,3$ & $1,2,3$ & 1,4 & $1,2,3$ & 2 & 2 \\
\hline Meyve rengi L değeri & $62.0 \pm 9.5$ & $40.6 \pm 2.5$ & $48.1 \pm 7.2$ & $49.0 \pm 3.5$ & $58.9 \pm 2.8$ & $45.5 \pm 3.1$ & $48.3 \pm 2.9$ & $51.4 \pm 3.2$ \\
\hline Meyve rengi a değeri & $17.9 \pm 3.5$ & $14.8 \pm 1.8$ & $18.0 \pm 2.3$ & $19.5 \pm 0.8$ & $11.5 \pm 0.9$ & $18.5 \pm 1.4$ & $19.9 \pm 1.1$ & $21.0 \pm 1.0$ \\
\hline Meyve rengi $b$ değeri & $34.7 \pm 2.3$ & $20.7 \pm 2.9$ & $25.8 \pm 5.7$ & $28.4 \pm 3.0$ & $27.0 \pm 0.3$ & $26.1 \pm 3.5$ & $27.7 \pm 3.1$ & $31.8 \pm 2.0$ \\
\hline Ortalama meyve ağırlığı (g) & $1.4 \pm 1.2$ & $2,1 \pm 1.6$ & $7.5 \pm 4.3$ & $4.6 \pm 1.8$ & $6.4 \pm 2.3$ & $3.8 \pm 2.0$ & $4.5 \pm 1.9$ & $5.3 \pm 0.5$ \\
\hline Bitki başına meyve sayısı (adet) & $443.6 \pm 19.7$ & $298 \pm 18.9$ & $133.7 \pm 3.9$ & $163.4 \pm 8.5$ & $200 \pm 5.6$ & $392 \pm 11.4$ & $339.2 \pm 10.3$ & $241 \pm 7.5$ \\
\hline Bitki başına meyve ağırlığı (g) & $49.7 \pm 12.8$ & $34.2 \pm 17.3$ & $84.8 \pm 17.6$ & $64.3 \pm 10.8$ & $83.9 \pm 10.8$ & $86.8 \pm 14.9$ & $96.5 \pm 17.9$ & $114.4 \pm 10.1$ \\
\hline Meyve ağırlığı (g) & $9.1 \pm 7.4$ & $12.1 \pm 9.8$ & $56.9 \pm 9.8$ & $33.6 \pm 13.9$ & $39.6 \pm 15.6$ & $23.6 \pm 15.6$ & $28.3 \pm 11.5$ & $43.2 \pm 8.0$ \\
\hline Meyve kuru ağırlığı (g) & $1.8 \pm 1.5$ & $1.7 \pm 1.1$ & $5.4 \pm 1.1$ & $3.3 \pm 1.3$ & $3.7 \pm 1.2$ & $2.7 \pm 1.4$ & $3.9 \pm 0.1$ & $5.2 \pm 0.4$ \\
\hline
\end{tabular}

Grup F: Dendrogramda bu grup içerisinde 20 genotip yer almıştır. Tüm gruplar içerisinde, alt grup (7) sayısının en fazla olduğu gruptur. Bu gruptaki genotiplerde meyve sap çukurunun az derin yapılı olduğu tespit edilmiştir. Bu popülasyonda ortalama meyve uzunluğu değeri, 57.7 $\mathrm{mm}$ olarak ölçülmüştür (Çizelge 8 ). Meyve şekilleri, genotiplere göre değişkenlik göstermiştir. Yapılan değerlendirme sonucunda meyve şekilleri; üçgen, kalp ve boynuz şeklinde tanımlanmıştır. Oldukça heterojen meyve şekillerine sahip olduğu belirlenmiştir.

Grup G: Alt grup sayısının çok fazla olduğu diğer bir gruptur. Genotiplerin ortalama gövde çapı değeri, 12.7 $\mathrm{mm}$ olarak bulunmuştur (Çizelge 8 ). C. baccatum türüne ait biber genotiplerinin yeşil meyve renginde oldukları tespit edilmiştir. Çiçek renginin beyaz-sarı tonlarında olduğu saptanmıştır. Meyve şekli (yuvarlak, üçgen, kalp, çan) bakımından ise oldukça heterojen bir grup olduğu tespit edilmiştir. 
Grup H: Bu grup içerisinde 1 adet $C$. baccatum genotipi yer almaktadır (Şekil 1). Bu genotip tüm özellikleri yönünden diğer $C$. baccatum genotiplerinden belirgin farklılıklar göstermiştir. Tek bir alt gruba ayrılmıştır. Biber genotipinin yaprak eni $(2.5 \mathrm{~cm})$ ve yaprak boyu $(4.8 \mathrm{~cm})$ değerlerinin diğer tüm gruplar içerisinde en yüksek olduğu saptanmıştır (Çizelge 8). CB-48 genotipinin meyve eni $(76.3 \mathrm{~mm})$ değerinin de oldukça yüksek olduğu bulunmuştur. Ayrıca gövdedeki antosiyanin renklenmesinin az düzeyde olduğu tespit edilmiştir.

\section{SONUÇ ve ÖNERILER}

C. baccatum türü içerisinde yer alan biber genotipleri; meyve şekli, meyve rengi, meyve iriliği, bitkide oluşan meyve sayıları, meyve ağılıkları, acılık ve tat seviyeleri yönünden oldukça yüksek düzeyde genetik çeşitlilik göstermektedir. Yabani formda bulunan Capsicum türleri, özellikle biyotik ve abiyotik stres koşullarına dayanıklılık başta olmak üzere birçok dayanıklılık özelliklerini oluşturan karakterleri genetik yapılarında taşımaktadırlar (Grubben, 1977; Pickersgill, 1980). C. baccatum türü, Güney Amerika dışında çok fazla tanınan bir biber türü değildir. Ülkemizde ise daha çok $C$. annuum türünün yaygın olması nedeniyle bu tür üzerinde bilimsel çalışmalar gerçekleştirilmiştir. Son yıllarda ise sayıları sınırlı da olsa diğer Capsicum türleri üzerinde de bazı çalışmalar yapılmaya başlanmıştır (Yaldız ve Özgüven, 2011; Eken ve Mavi, 2014; Mavi ve ark., 2018; Taş, 2020). $\mathrm{Bu}$ araştırma ile $C$. baccatum türüne ait biber genotiplerinin Samsun ekolojik koşullarında adaptasyon yeteneklerinin belirlenmesi ve bitki özellik belgeleri oluşturularak biber çeşit ıslah programlarında değerlendirme imkanları ayrıntılı olarak incelenmiştir. Çalışma sonucunda Dünya'nın farklı coğrafik bölgelerinden toplanmış olan $C$. baccatum türüne ait biber genotiplerinin morfolojik özellikleri yönünden belirgin farklılıklar gösterdikleri ve heterojen nitelikte bir gen havuzunun oluşturulduğu ortaya konulmuştur. Halen mevcut genetik kaynaklarda moleküler düzeyde karakterizasyon çalışmaları ve seleksiyon ıslahı programına devam edilmektedir.

\section{ÖZET}

Amaç: Capsicum baccatum türüne ait 67 biber genotipinin UPOV (Uluslararası Yeni Bitki Çeşitlerini Koruma Birliği) bitki özellik belgesi kriterlerine göre morfolojik özelliklerinin tanımlanması ve bitkisel özellikleri yönünden $C$. baccatum türüne ait biber popülasyonunda var olan mevcut varyasyon düzeyinin belirlenmesi amaçlanmıştır.

Yöntem ve Bulgular: Araştırmada, C. baccatum türüne ait popülasyonda UPOV tarafından biber için belirtilen TG/76/8 nolu bitki çeşit özellik belgesine göre morfolojik karakterizasyon yapılmıştır. Morfolojik tanımlama kriterleri yönünden $C$. baccatum türüne ait biber genotiplerinin yüksek düzeyde fenotipik çeşitlilik gösterdikleri saptanmıştır. Elde edilen verilere, küme ve temel bileşen analizi uygulanmıştır. Temel bileşen analizi sonucunda $C$. baccatum türüne ait biber popülasyonunda morfolojik varyasyon değerinin \%75.75 oranında olduğu belirlenmiştir. Bu sonuç, C. baccatum türüne ait biber genotipleri arasında yüksek oranda morfolojik varyasyon bulunduğunu göstermiştir. Ayrıca, küme analizi sonucunda $C$. baccatum genotiplerinin akrabalık ilişkilerinin tespit edildiği bir benzerlik dendogramı da elde edilmiştir.

Genel Yorum: Araştırma sonucunda, morfolojik tanımlama kriterleri yönünden $C$. baccatum türüne ait biber genotiplerinin yüksek düzeyde çeşitlilik gösterdikleri saptanmıştır.

Çalışmanın Önemi ve Etkisi: $\mathrm{Bu}$ çalışma ıslah programının ilk aşamasını kapsamaktadır. Araştırma sonrasında, incelenen gen havuzundan seçilecek genotiplerin çeşit ve anaç ıslah programında değerlendirilmesine yönelik çalışmalara devam edilmesi planlanmaktadır.

Anahtar Kelimeler: C. baccatum, çeşitlilik, genotip, tanımlama, varyasyon.

\section{TEŞEKKÜR}

Bu araştırma, Aslı Kanal'ın Ondokuz Mayıs Üniversitesi, Lisansüstü Eğitim Enstitüsü, Bahçe Bitkileri Ana Bilim Dalında tamamlanmış olan yüksek lisans tez çalışmasının bir kısmından üretilmiştir.

\section{ÇIKAR ÇATIŞMA BEYANI}

Makale yazarları aralarında herhangi bir çıkar çatışması olmadığını beyan ederler.

\section{ARAŞTIRMACILARIN KATKI ORANI BEYANI}

Yazarlar makaleye eşit oranda katkı sağlamış olduklarını beyan ederler.

\section{KAYNAKLAR}

Agyare RY, Akromah R, Abdulai MS (2016) Assessment of genetic diversity in pepper (Capsicum sp.) landraces from Ghana using agro-morphological characters. Am. J. Exp. Agric. 12(1): 1-16.

Balkaya A, Yanmaz R (2001) Bitki genetik kaynaklarının muhafaza imkanları ve tohum gen bankalarının çalışma sistemleri. Ekoloji Çevre Derg. 10(39): 25-30. 
Balkaya A, Yanmaz R, Apaydın A, Kar H (2005) Morphological characterization of white head cabbage (Brassica oleracea var. capitata subvar. alba) genotypes in Turkey. N. Z. J. Crop Hortic. Sci. 33: 333341.

Balkaya A, Özbakır M, Karaağaç O (2010) Karadeniz Bölgesinden toplanan bal kabağı (Cucurbita moschata Duch.) populasyonlarının karakterizasyonu ve meyve özelliklerindeki varyasyonun değerlendirilmesi. Ankara Tar. Bil. Derg. 16(1): 17-25.

Barboza GE, Garcia CC, Gonzalez SL, Scaldaferro M, Reyes X (2019) Four new species of Capsicum (Solanaceae) from the tropical Andes and an update on the phylogeny of the genus. PloS One 14(1): e0209792.

Bliss FA (1981) Utilization of vegetable germplasm (Ploidy levels). Hortsci. 16(2): 129-132.

Brown JS (1991) Principal component and cluster analysis of cotton cultivar variability a cross the U.S. Cotton Belt. Crop Sci. 31: 915-922.

Castro SP, Dávila MAG (2008) Caracterización morfológica de 93 accesiones de Capsicum spp del banco de germoplasma de la universidad nacional de colombia - sede palmira. Acta. Agron (Palmira) 57(4): 247-252.

Cherian EV, Indira P (2003) Variability in Capsicum chinense Jacq. Germplasm. Capsicum and Eggplant Newsletter 22: 39-43.

Costa LV, Bentes JLS, Lopes MTG, Alves SRV, Vıana Júnıor, JM (2015) Caracterização de acessos de pimentas do Amazonas. Hortic. Bras. 33: 290-298.

Eken Ni, Mavi K (2014) Çan biberinde (Capsicum baccatum var. pendulum) meyve olgunluk dönemleri ile tohum gelişimi ve kalitesi arasındaki ilişkilerin belirlenmesi. Tar. Bil. Derg. 22(1): 69-76.

Eshbaugh WH, Russo VM (2012) The taxonomy of the genus Capsicum. In: Peppers Botany, Production and Uses (Ed. Russo V). CAB International, UK. 14-28s.

García-Neria MA, Rivera-Bustamante RF (2011) Characterization of geminivirus resistance in an accession of Capsicum chinense Jacq. Mol. Plant Microbe Interact. 24(2): 172-182.

Grubben GJH (1977) Tropical vegetables and their resources. IBPGR: International Board for Plant Genetic Resources. Rome, Italy pp. 197

Greenleaf WH (1986) Pepper Breeding. Breeding Vegetable Crops. CAP International. The Cambridge University Press. UK. 76-82.

Jarret RL (2007) Morphologic variation for fruit characteristics in the USDA/ARS Capsicum baccatum L. germplasm collection. Hortsci. 42(5):1303-1305.
Karaağaç O (2006) Bafra kırmızı biber gen kaynaklarının (Capsicum annuum var. conoides Mill.) karakterizasyonu ve değerlendirilmesi. Yüksek Lisans Tezi, Ondokuz Mayıs Üni., Fen Bil. Ens., Bahçe Bitkileri ABD, 129s.

Karaağaç O, Balkaya A (2010) Bafra kırmızı biber populasyonlarının [Capsicum annuum L. var. conoides (Mill.) Irish] tanımlanması ve mevcut varyasyonun değerlendirilmesi. Anadolu Tar. Bil. Derg. 25(1): 10-20.

Karaağaç O (2013) Karadeniz Bölgesinden toplanan Kestane Kabağı (C. maxima duchesna) ve Bal Kabağı (C. moschata Duchesne) genotiplerinin karpuza anaçlık potansiyellerinin belirlenmesi. Doktora Tezi, Ondokuz Mayıs Üni., Fen Bil. Ens., Bahçe Bitkileri ABD, 258s.

Karaağaç O, Balkaya A (2017) Türkiye'de yerel sebze çeşitlerinin mevcut durumu ve ıslah programlarında değerlendirilmesi. TÜRKTOB 23(6): 8-15.

Luitel BP, Ro NY, Ko HC, Sung JS, Rhee JH, Hur OS (2018) Phenotypic variation in a germplasm collection of pepper (Capsicum chinense Jacq.) from Korea. J. Crop Sci. Biotech. 21(5): 499-506.

Mavi K, Mavi F (2012) Capsicum baccatum var. pendulum türüne ait biber hattının tohumlarında çimlenme için uygun sıcaklı̆ı̆ belirlenmesi. MKU Zir. Fak. Derg. 17(2): 79-86.

Mavi K, Mavi F (2015) Bazı süs biberi genotiplerinin tohumluk bitki özellikleri ve tohum çıkış performansları. Dicle Üni., Fen Bil. Ens. Derg. 4(1): 3135.

Mavi K, Uzunoğlu F, Hacbekir H, Kaya S (2018) Biber denince eşsiz bir lezzet: Capsicum baccatum. BIPP. 201. Kasım: p. 32.

Özdamar K (2004) Paket Programlar ile İstatiksel Veri Analizi (Çok Değişkenli Analizler), Eskişehir. 528s

Padilha HKM, Vasconcelos CS, Villela JCB, Valgas RA, Barbieri RL (2016) Agronomic evaluation and morphological characterization of chili peppers. Capsicum annuum. Solanaceae. from Brazil. Aust. J. Basic Appl. Sci. 10(13): 63-70.

Patel K, Calderon R, Asencios E, Vilchez D, Marcelo M, Rojas R (2016) Agro-morphological characteristics and sensory evaluation of native peruvian chili peppers. J. Agric. Sci. Tech. B, 6: 180-187.

Pickersgill B (1980) Some aspects of interspecific hybridization in Capsicum. In Preliminary report at The 4th EUCARPIA Capsicum working group meetings, October. Wageningen, Netherlands. pp. 14-46. 
Rohlf FJ (1993) Numerical Taxonomy and Multivariate Analysis System. Exeter Software, Dept. Of Ecology and Evolution, State University of New York. NTSYSpc 16(2): 197-223.

Sreenivas $M$, Sharangi $A B$, Banerjee $S$, Bhattacharya $T$, Maurya PK, Chattopadhyay A (2019) Characterization and evaluation of indigenous and exotic genotypes for identification of spice chilli lines. IJCS 7(2): 18301837.

Taş K (2020) Capsicum chinense türüne ait biber genotiplerinin morfolojik ve moleküler karakterizasyonu. Yüksek Lisans Tezi, Ondokuz Mayıs Üni., Lisansüstü Eğitim Ens., Bahçe Bitkileri ABD, 95s.

TTSM (2019) T.C. Tarım ve Orman Bakanlığı Tohumluk Tescil ve Sertifikasyon Merkez Müdürlüğü. https://www.tarimorman.gov.tr/BUGEM/TTSM/Me nu/30/Kayit-Listeleri (Erişim tarihi: 13 Şubat 2019).

UPOV (2006) International union for the protection of new varieties of plant. Mcguire RG (1992) Reporting of objective color measurements. HortScience 27: 1254-1255.
Velázquez-Ventura JC, Márquez-Quiroz C, Cruz-Lázaro EDL, Osorio-Osorio R, Preciado-Rangel P (2018) Morphological variation of wild peppers (Capsicum spp.) from the state of Tabasco, Mexico. Emir. J. Food Agric. 30(2): 115-121.

Villota-Cerón D, Bonilla-Betancourt ML, Carmen-Carrillo H, Jaramillo-Vásquez J, García-Dávila MA (2012) Morphological characterization of accessions of Capsicum spp. from the germplasm collection of the Colombian corporation for agricultural research (corpoica) C.I. Palmira. Acta Agronomica 61(1): 16-26.

Yaldız G, Özgüven M (2011) Farklı süs biberi (Capsicum Sp.) tür ve hatlarının Çukurova koşullarına adaptasyonu. Yüzüncü Yıl Üni. Tar. Bil. Derg. 21(1): 111. 